\title{
Cooperation and Authoritarian Values: An Experimental Study in China
}

Bjöern Vollan, Andreas Landmann, Yexin Zhou, Biliang $\mathrm{Hu}$, Carsten Hermann-Pillath

Working Papers in Economics and Statistics

2013-14 


\section{University of Innsbruck \\ Working Papers in Economics and Statistics}

The series is jointly edited and published by

- Department of Banking and Finance

- Department of Economics

- Department of Public Finance

- Department of Statistics

Contact address of the editor:

Research platform "Empirical and Experimental Economics" University of Innsbruck

Universitaetsstrasse 15

A-6020 Innsbruck

Austria

Tel: $\quad+435125077171$

Fax: $\quad+435125072970$

E-mail: eeecon@uibk.ac.at

The most recent version of all working papers can be downloaded at http://eeecon.uibk.ac.at/wopec/

For a list of recent papers see the backpages of this paper. 


\title{
Cooperation and Authoritarian Values: An Experimental Study in China
}

\author{
Björn Vollan ${ }^{\mathrm{a}}$, Andreas Landmann ${ }^{\mathrm{b}}$, Yexin $\mathrm{Zhou}^{\mathrm{c}}$, Biliang $\mathrm{Hu}^{\mathrm{c}}$, Carsten Herrmann-Pillath ${ }^{\mathrm{d}}$
}

\begin{abstract}
There is ample evidence of a "democracy premium." Using field data and laboratory experiments, it has been observed that democratic governance leads to more cooperative behavior compared to a non-democratic approach. We present evidence from Chinese students and workers who participated in public goods experiments and a value survey. We find a premium for top-down rule implementation arguably stemming from people with stronger individual values for obeying authorities. When participants have higher values for obeying authorities, they even conform to unfavorable rules. Our findings provide evidence that the effectiveness of a political institution depends on its congruence with individual values and societal norms.
\end{abstract}

Keywords: legitimacy of legal sanctions, authoritarian values, democratic voting, public goods, China

JEL: A13, C92, D02, D72, H41

a) Corresponding author: University Innsbruck, Department of Public Finance, Universitätsstraße 15,6020 Innsbruck, Austria.bjoern.vollan@uibk.ac.at

b) University of Mannheim, Department of Economics, L7, 3-5, 68131 Mannheim, Germany.

c) Beijing Normal University, School of Development Studies, School of Economics and Resource Management, No. 19, Xinjiekouwai Street, Beijing 100875, China

d) Witten/Herdecke University, Chair of Economics and Evolutionary Sciences, AlfredHerrhausen-Straße 50, 58448 Witten, Germany.

Acknowledgements: We are thankful to Qingchao Wang, Wei Yuan, Xiangdong Sun, Fei Xiong, Wei Tang, Fei Yang and Qian Wan for their enthusiastic research assistance. Funding for this project comes from the "985 Project" of Beijing Normal University. We are grateful for constructive comments from Esther Blanco, Eric Coleman, Bernd Hayo, Michael Kosfeld, Antonio Nicolò, Rupert Sausgruber, Elisabeth Sadoulet, Sebastian Prediger, Hannelore WeckHannemann and workshop and conference participants in Innsbruck (Oct. 4, 2012), Berkeley (Nov. 29-30, 2012) Hamburg (May 29, 2013) EEA in Gothenburg (Aug. 26-30, 2013), Zürich (Nov. 22-23, 2013) Göttingen (July 2-4, 2014), Mannheim (Dec. 15, 2014), as well as to Lars Feld for providing instructions for their experiment. All remaining errors are ours. 
And economies that adopt the formal rules of another economy will have very different performance characteristics than the first economy because of different informal norms and enforcement.

Douglass North (1993), Nobel lecture

\section{Introduction}

Institutions are the humanly devised constraints that structure human interaction (North 1990). They are made up of formal constraints (rules, laws, and constitutions) and informal constraints (norms of behavior, conventions, and self-imposed codes of conduct). The interplay of both is said to be important in explaining economic development and especially the successful transformation of societies into market economies. Moreover, Douglass North $(1990 ; 1993)$, Samuel Bowles (1998), and Elinor Ostrom (2000) pointed out that norms of behavior, values, and tastes evolve within a certain economic, social, ecological, and cultural contexts and their interaction with implemented formal rules or policies is unclear or needs to be evaluated case by case (Ostrom 2000). Hence, formal rules may perform differently depending on the underlying set of personal values and informal norms. Hay, Shleifer, and Vishny (1996) mention — among several other factors - the importance of achieving congruence between prevailing social norms and laws. Despite the insights from these prominent academics, much political debate still centers on blueprint policy prescriptions and panacea solutions that do not account for local context factors. One reason may be that there exists, to our knowledge, no strong empirical evidence that supports this conjecture. In this paper, we investigate the interplay of individual values for acceptance of authority and how people with such values perform under democratic decision making compared to non-democratic decision making. Using samples of both students and workers in China, we show that Chinese participants cooperate the most under an exogenously imposed law which is in line with authoritarian norms, which are undoubtedly very prominent in 
China. ${ }^{1}$ We further show that there is a systematic association between participants' values and their relative contribution decisions in exogenous and endogenous implementation of the law. Our major result is that those subjects with high values of accepting authorities are responsible for the higher cooperation under top-down governance.

One of the most widespread assumptions in economics, political science, development studies, or management sciences is that institutions that enable participation in decision-making increase the motivation of individuals to cooperate. Empirical evidence from studies on participation in the workplace (Ichniowski and Shaw 2003; Zwick 2004), public participation to foster development (Casey, Glennerster and Miguel 2012), the provision of public goods (Pommerehne and Weck-Hannemann 1996) or the management of common pool resources (Bardhan 2000) highlights higher cooperation with the use of democratic principles as well as higher satisfaction among community members in participatory processes (Olken 2010). The link between participation and positive motivation to cooperate seems straightforward because agreeing with certain decisions means that the subsequent actions conform to individual preferences. One possible explanation is that democratic participation increases selfdetermination, sense of personal control and actors' intrinsic motivation to cooperate with each other (Frey and Oberholzer-Gee 1997). In contrast, externally imposed policies can crowd-out this intrinsic motivation to cooperate (Bowles 2008), and a lack of perceived autonomy is a major factor in driving the crowding-out of intrinsic motivation (Deci, Koestner and Ryan . 1999). Thus, higher levels of democratic participation increase the individual motivation to cooperate, on whichever level of social organization, such as shared goals in a company or responsible behavior of citizens in a nation.

\footnotetext{
${ }^{1}$ We use the term "value" whenever we refer to ideals people have or the desirability of certain actions elicited from survey items at the individual level. We refer to "norms" when we compare behavioral regularities between countries. Often the norms support the personal values. However, a person can have a relatively low valuation of accepting authorities but at the same time live in a country where most people follow hierarchical norms.
} 
There is also a small but illuminating literature in experimental economics that vindicates the higher cooperation under democratic elected laws (Ostrom, Walker and Gardner 1992; Alm, McClelland, and Schulze 1999; Walker et al. 2001; Decker, Stiehler and Strobel 2003; Tyran and Feld 2006; Ertan, Page and Putterman 2009; Dal Bo, Foster, and Putterman 2010; Sutter, Haigner, and Kocher 2010; Kube et al. 2014; Kamei, Putterman, and Tyran 2015, Markussen, Putterman, and Tyran 2015). Furthermore, the meta-analysis in social psychology (Foels et al. 2000), covering 19 independent studies, also reports a positive significant effect for democratic leadership in triggering satisfaction and cooperation. The experimental literature mainly uses public goods games as the workhorse for studying cooperation, thus defining cooperation explicitly as the willingness to cooperate in spite of individual incentives to exploit others in order to maximize individual gain (free riding). Sutter, Haigner, and Kocher (2010: p.1563) conclude that "the option of participating democratically in the choice of institutions makes the difference".

However, these conventional laboratory studies cannot explore the initial statements by North $(1990 ; 1993)$ and Ostrom (2000) that formal institutions may lead to different results in terms of effectiveness if they interact with different informal constraints like societal norms and values. In western societies, education has fostered normative principles for decades, which undergird behavior leading to the positive democracy premium. Thus, legitimacy of a law is gained by using fair procedures. Additionally, the previous experiments were carried out without eliciting personal values to analyze the determinants of the cooperation-enhancing effect of democracy. In our novel study, we resolve these two shortcomings by combining controlled laboratory experiments (carried out with students and workers), with a broad set of value questions asked to the same group of participants, in order to explain their behavior in the laboratory experiment. 
Besides the rational-legal legitimacy stemming from institutional procedures, Weber (1968) mentions that legitimacy may also be derived from traditions and charismatic leadership. While in Western democracies, fair procedures such as majority voting are seen as a way to legitimize authority, one of the most conspicuous examples of distinct normative foundations is the decades-long debate over East Asian societies, often conflated under the term "Confucian societies", in particular China, Japan, and Korea. These societies apparently support a long tradition of authoritarian paternalism in enterprise management or government, the family and educational system (Farh et al. 2008; Liu, Li, and Yue 2010). Empirical support for this hypothesis has been garnered by large scale value surveys, in which those societies appear to be especially strong in the dimensions of "collectivism", "long-term orientation" and "power distance" (Hofstede, Hofstede and Minkov 2010). A high power distance implies, according to Hofstede, Hofstede and Minkov (2010) that respect for authority is a social norm and there is little discussion and subordinates expect to be told what is to be done. Also, the GLOBE study on leadership identifies similar "Confucian" values (House et al. 2004), and the study of Inglehart and Welzel (2005) suggests that China has very low "self-expression values" and thus, very little demand for participation in economic and political decision-making. Thus, it is likely that legitimacy may be gained by exogenous laws in China since the individual values for traditional authority governance are high and distinct while the traditional values for authority rather act as substitutes or even stand in conflict with democratic or participatory decision making. Therefore, we expect that, in China, average contributions in non-democratic regimes will be higher than contributions with democratic regimes (unconditional democracy hypothesis). We corroborate our finding by testing a more nuanced conditional democracy hypothesis which states that contributions in non-democratic regimes will be higher than those with democratic regimes for people with high deference to authority. We test this in two ways: First, by comparing a sample 
of workers (high deference to authority) to a sample of students (lower deference to authority) and second, by investigating individual values of deference to authority and contribution to exogenous law.

We combine two subject samples, one sample taken from rapidly modernizing rural China. This is a group of 150 migrant workers with rural backgrounds who work in a company, which combines modern factory management with a strong emphasis on Confucian values. The other sample is taken from the students of a top-level university located in the capital of Beijing, which is open to cosmopolitan influences. We elicit the motivation to contribute by a series of randomly ordered, independent, anonymous, one-shot public goods games. In one variant of the game, participants make contributions without a law (ExoNoLaw), in another one with the law (ExoLaw), and in a third variant, participants have to vote for the introduction of the law and are informed about voting behavior of other participants of the other group members (Endo). In line with our unconditional democracy hypotheses we show that in both samples contribution are highest under exogenous law and that a non-democratic regime leads to higher average contributions.

Concerning our conditional democracy hypothesis we show that the student subject pool shows some positive effects of endogenous rule and that there is a systematic association between participants' values and their relative contribution decisions in exogenous and endogenous implementation of the law. Our major result is that those subjects with high values of accepting authorities are responsible for the higher cooperation under top-down implementation. They react to the law with increasing cooperation regardless if they are in favor with the law or not. We further find that participants with lower values of accepting authorities cooperate more when the law is implemented in a democratic procedure which comes close to the results obtained in Western countries. Our result is also consistent with the only cross-cultural experiment on that 
topic that we are aware of. Iyengar and Lepper (1999) examined the effect of individual choice (not democratic choice) on intrinsic motivation using both Anglo American and Asian American children from two schools in San Francisco. Iyengar and Lepper (1999) found that while Anglo American children showed the highest intrinsic motivation solving anagrams when they could make their own choices about marker colors and anagram topics, Asian American children, however, were most intrinsically motivated when choices were made for them by their mothers.

Our study supports the view that congruence of values, norms, and rules is important to gain legitimacy of governance regimes.

\section{Methods}

Our set-up with workers in China required us to implement the experiments with pen and paper. This is one reason why we mainly followed the experimental protocol of Tyran and Feld $(2006) .^{2}$ As stated above, similar results are found in a range of experimental studies using different designs but our aim is not to directly compare those studies. However, the "democracy premium" in the Western world seems robust to changes of design characteristics.

\subsection{The public good experiment with (non) democratic law}

In our linear public good experiment, $\mathrm{n}$ players are randomly paired in a one-shot and anonymous interaction. Each of the players receives an endowment $\mathrm{y}_{\mathrm{i}}$ and has to decide anonymously and simultaneously on his or her contribution to a public good $\mathrm{g}_{\mathrm{i}}$ or private good $\mathrm{c}_{\mathrm{i}}$, where $c_{i}=y_{i}-g_{i}$. Each subject's income from the public good is the fractional amount a

\footnotetext{
${ }^{2}$ Another reason is that we believe their way of introducing direct democracy is very intuitive to subjects and does not incur any potential psychological adaptations for not obtaining one's desired outcome. Other experiments (e.g. Dal Bo et al. 2010) have used a random device to determine whether the computer allows participants to continue to play with their vote or not.
} 
multiplied by the sum of contribution by all $\mathrm{j}=1, . ., \mathrm{n}$ group members to the public good $\sum_{j=1}^{n} g_{j}$. Total payoff is given by $\pi_{i}=y_{i}-g_{i}+a \sum_{j=1}^{n} g_{j}$. The marginal return from the public good is $\mathrm{a}=0.5$, group size $n=3$, and initial endowment $y_{i}=10$. The game constitutes a cooperation dilemma because together, players are best off if all three contribute their entire endowment to the public good $\left(g_{i}=y_{i}\right)$; however, because the individual cost of contributing one point to the public good is one but the return is only 0.5 , the dominant strategy of a selfish player is contributing zero to the public good, independent of the other player's contribution.

The law prescribes full contribution to the public good. Contributions of less than ten points lead automatically to a sanction of two points. The law, however, does not change the equilibrium prediction of contributing nothing to the public good for subjects that only care about their monetary payoffs. In case of a sanction, the payoff is $\pi_{i}=y_{i}-g_{i}+a \sum_{j=1}^{n} g_{j}-s_{i}$ where $\mathrm{s}_{\mathrm{i}}=0$ if $\mathrm{y}_{\mathrm{i}}=$ $g_{i}$ and $s_{i}=2$ if $g_{i}<y_{i}$. Full contribution is rational when $\pi_{i}($ full $)>\pi_{i}$ (zero), i.e., if $s_{i}>y_{i}(1-a)$. The equilibrium strategy of zero contribution yields a payoff of 10 tokens in ExoNoLaw and 8 tokens in Law. The game theoretic predictions for voting are obtained through backward induction. In the first stage, people vote on the sanction, and in the second stage, they make their contribution decisions. Thus, knowing that the law does not deter money maximizers from defecting it is irrational to vote for the sanction, since the payoff in the equilibrium prediction is $\pi_{\mathrm{i}}($ NoLaw $)>$ $\pi_{\mathrm{i}}($ Law $)=10>8$. We only chose a non-deterrent sanction since we are interested in investigating intrinsic motivations to cooperate. Many real-life interactions related to honesty or cooperation are subject to non-deterrent sanctions and intrinsic motivations. In many instances, the benefits of improperly filing taxes, overstating the claims to insurance, shirking co-workers, and downloading illegal music and films from the internet outweigh the probability of getting caught 
and the corresponding costs (Mazar and Ariely 2006). Relatedly, (non-deterrent) laws are important not only for their material incentives, but also for prescribing what people ought to do (Sunstein 1996; Posner 1998). This expressive function of the law helps in shaping the values of society (Galbiati and Vertova 2008). Thus, non-deterrent laws signal appropriate behavior and might indeed deter many individuals, even though monetary incentives are weak.

In the first round of the experiment we also identified each participants' type, as proposed by Fischbacher, Gächter, and Fehr (2001). Controlling for player types could be important because conditional cooperators should especially respond to the endogenous rule implementation. In other words, they should react more to the information on the co-players' voter types delivered through the election process.

From round two onwards we have a randomized blocked design where our blocking factor is whether our subjects are students or workers. The experimental treatments vary in two dimensions: First, whether there is a (non-deterrent or mild) sanction or not and second how the sanction is enacted. The law can either be exogenously imposed or endogenously chosen through majority voting (if two out of three subjects vote for the law). The following three treatments were randomly implemented as within subject design for both students and workers:

- ExoNoLaw: The deduction rule is not implemented and participants play a normal version of the public good game.

- ExoLaw: The deduction rule of two points for not contributing all endowment to the public good is imposed on participants.

- Endo: Players vote whether or not to have the deduction rule that deducts two points for not contributing all endowment to the public good (strategy method). 


\section{(insert Table I here)}

In the Endo treatment the subjects do not learn the actual distribution of votes in their group, but they had to make their contribution decisions contingent on (i) whether no other person voted for the rule (Endo0: the rule is not implemented), (ii) one other person voted for the rule (Endol: own previous voting decision determines whether rule is in place), or (iii) two other people voted for the rule (Endo2: the rule is implemented). Based on the voting outcome within each group, we can identify which of the three decisions (Endo0, Endo1, Endo2) was finally payoff relevant to show the outcomes of endogenous law in the descriptive analysis labeled as Endo. Note that a comparison between contributions under Endo and ExoLaw is interesting but not a valid computation of the democracy premium. In order to calculate a causal democracy effect (i.e. comparing two regimes that implement the same law) one needs to take into account that sometimes laws get enacted and sometimes they don't get enacted. Thus, besides only comparing EndoLaw to ExoLaw (i.e. when rules are implemented) one also needs to compare EndoNoLaw to ExoNoLaw. We turn to this more technical identification of the top-down versus bottom-up regime in section 3.2 and the supplementary appendix.

By using the strategy method in the Endo treatment, we can identify how participants react to the voter distribution (information effect) and we avoid selection effects between groups implementing and not implementing the law (i.e. more cooperative subjects vote for the law that supports cooperative behavior). The evidence by Tyran and Feld (2006) suggests that there can be a quite substantial positive effect of endogenous rule implementation with this strategy method.

We chose a within-subject design which holds individual-specific factors constant as it enables us to correlate the democracy premium with societal values which is the major contribution of out paper (section 3.3). Note, however, that we have a between-subject design for 
round two (the first where treatments were introduced) with almost 300 subjects where we find similar results, as in the within-subject design suggesting that "carryover effects" did not affect the relative effects of our three treatments (see supplementary Appendix for further details). Furthermore, the orders of the rounds were changed between sessions to control for possible ordering or "carryover effects". The orders of the rounds are presented in the online appendix in Tables A.1-A.3.

After each round, each subject was randomly matched with two other subjects. Information about each other's contribution level was never revealed and earnings were given to participants after the final rounds to keep the treatments independent from each other. Participants only knew their own contribution in a certain setting and were not allowed to alter these decisions in a new treatment round.

Additionally, we tested for one other arrangement, labeled EndoPay, that we only applied on the student sample due to its complexity. ${ }^{3}$ In this case, if there are two players willing to pay for the voting out of their show-up fees we implemented treatment Endo; if not we randomly determined whether ExoLaw or ExoNoLaw was played (analysis of EndoPay is available in the online appendix). In total, $31 \%$ of students were willing to pay in order to vote. Effects found in the main analysis can be confirmed in the EndoPay treatment. We do not find stronger overall democracy effects if people have to pay for voting. We further find that people who are willing to take risks especially pay for the right to vote.

\subsection{Implementation of the experiment}

A total of 300 subjects participated in the experiment. One worker could not finish the experiment, leaving us with 299 observations: 150 students and 149 workers. All participants

\footnotetext{
${ }^{3}$ With the additional treatment (EndoPay), we can confirm that our results also hold when all treatments are using the strategy method (ExoNoLaw (2.8), Endo (3.3), ExoLaw (4.7); see supplementary appendix).
} 
passed the control questions about understanding the experiment. One experimental session comprised of 30 subjects. The first five sessions were carried out with students at Beijing Normal University (BNU), and the final five sessions were with workers from Fuxing village in Hubei province. Participants were all seated in one room, and each participant was seated at a separate table. Recruitment of students was done with flyers and through the Bulletin Board System on the BNU campus; workers were recruited with help of managers at Fuxing Tech Co., Ltd. The recruiters at Fuxing were only told that we needed workers willing to take part in a scientific experiment on decision-making, where they could earn a certain amount of money. The workers from a working group volunteered until there were 30 volunteers per session. In both cases there was no pre-selection by professors, the company manager, or even party officials. The participants were also not aware of the fact that one of the experimenters was a foreigner. One Chinese speaking senior scientist was always present and visible to the participants. In both settings, the experiments were conducted by a team of seven Chinese research students who received extensive training and were under our supervision. However, the assistants/recruiters were not told the purpose of the study. The same research assistant read and explained the experiment during all ten sessions. Students were randomly allocated to the different sessions, while workers remained within their usual working teams; this was necessary because workers had to participate during the same time slots after work. However, we intentionally exploited this difference in our analysis because the worker sample, for that very reason, represents a high-trust and high-obedience reference case. The experiments were pre-tested and translated between English and Chinese. We used different posters to visualize the experimental set-up and asked several test questions before each round. Each session consisted of four independent rounds (5 rounds for students). 
After all rounds and the questionnaire were completed, we randomly paid out three rounds. In total, subjects earned an average of 82.16 yuan (equivalent to 9.88 euro), including a show-up fee of ten yuan. This average payment is about equal to three hours' wage for a university student or 4 hours' wage for a worker. Experiments lasted between two to three hours, including the final questionnaire on socio-demographics and values.

\subsection{Background: Socio-demographics and values of students and workers}

China is, according to popular indexes, ranked as authoritarian regime and "not free" (Democracy Index 2011 or Freedom in the World 2012). However, it is often claimed that education supports the transition to democracy (Lipset 1959; Barro 1999). Hence, the two samples of workers and students represent evolving value systems in Chinese society. The rural workers may hold more traditional values because of both acculturation and the typical workplace setting of Chinese companies, which manifests high degrees of paternalistic authoritarianism; this is a pattern that also prevailed in non-communist Chinese societies and is bolstered in the context of the People's Republic (Chen and Farh 2010). In contrast, current students represent the single-child generation who grew up under the conditions of the rapid transformation of marketized, reformed China and also received strong international impacts in contemporary metropolitan society (Kulich and Zhang 2010).

Descriptive results of our two subpopulations are found in Table II. Students represent a relatively affluent generation of "single children." At the mean age of almost 22 years, they have already spent a larger part of their undergraduate studies at the university and therefore have the experience of living independently from their parents. The student lifestyle is strongly embedded into communitarian arrangements of everyday life (student dormitories, canteens, etc.). It allows for much larger degrees of individual freedom than, especially, during the last years of high 
school education. The worker sample is very different from this background. Most of the workers are migrant workers from all over China's mainland. Since the factory belongs to a company in a male-dominated manufacturing industry, the majority of the workers are male $(80 \%)$, many of them are married (44\%) with the average age of 33 , have been working for the company for about 10 years $(\operatorname{mean}=9.28, \quad$ s.d. $=7.62, \min =1, \max =25)$, and have similar incomes $($ mean $=2214.17$, s.d. $=847.52)$ and hierarchical positions within the company (only $3 \%$ have a monthly income above 4000 yuan).

After the experiment, participants filled in a questionnaire about socio-demographics as well as a set of questions from established value surveys, such as their values towards accepting authorities (Feldman 2003), collectivism (Torelli and Shavitt 2010; Shavitt et al. 2006), locus of control (Naditch 1974), and competitiveness/vertical individualism that emphasizes hierarchy (Triandis and Gelfand 1998). We also included items to measure the demand for punishment (Altemeyer 1988; Duckitt and Sibley 2010). Altogether, we asked 21 socio-psychological questions that we reduced to five factors (obey authority, collectivism, competitiveness, locus of control, and demand for punishment) using principal-component factor analysis as described in the online appendix. The two samples differ in many respects. Of particular importance within the context of this study is the difference in "obey authority" or "acceptance of authority." The students are significantly less accepting than the workers, possibly due to their age or the liberal environment at universities. The other difference between the two samples is that students reported to be less competitive. The latter result is not too surprising given the study by Cameron et al. (2013), who found that people born after the introduction of the one-child policy (no older than 32 years) are less competitive. All the students were born after the one-child policy but only $45 \%$ of the workers. Since the responses to the survey items are not incentivized they might be influenced by the experiment. However, we explicitly used survey questions e.g., regarding 
obeying authorities that are very unrelated to the game itself; the scores on these particular questions were similar to those reported in the World Value Survey in China. Furthermore, all subjects took part in the same experimental treatment such that they should not be influenced differently. Lastly, participants did not know their earnings at the time they filled in the survey. Thus, they were unaware of how successful their strategies were or what other people might have chosen.

According to the classification used by Fischbacher, Gächter, and Fehr (2001), we have $49 \%$ conditional co-operators in the pooled sample ( $47 \%$ only for students), $9 \%$ free-riders (14\% for students), $4 \%$ altruists ( $1 \%$ for students), $4 \%$ triangle contributors ( $6 \%$ for students) and $33 \%$ that cannot be classified ( $32 \%$ for students). Both samples show a similar share of conditional cooperators and these figures are overall consistent with those obtained from Kocher, et al. (2008) on three continents underlining a culturally independent pattern of player types. Thus, any differences in treatment effects should not be related to systematic differences in norms to cooperate, but rather to norms about democracy. Differences between our samples are mainly reflected by the differences in the extreme behaviors, i.e., free-riding and altruism.

(insert Table II here)

\section{Empirical results}

\subsection{Top-down and bottom-up policies in China}

In total, $42 \%$ of participants vote for and 58\% against the law in the endogenous treatment, leading to a total of $37 \%$ of groups enacting the law and $63 \%$ not enacting the law. The $58 \%$ of individuals voting against the law are very comparable to the $50 \%$ obtained by 
Tyran and Feld (2006), The $63 \%$ of groups not enacting the law are comparable with the $53 \%$ by Dal Bo, Foster, and Putterman (2010) or the $63 \%$ by Sutter, Haigner, and Kocher (2010), suggesting that there are no different preferences for the law itself in China. ${ }^{4}$

In the pooled sample of workers and students, we find that contributions under ExoNoLaw are on average $47 \%, 50 \%$ for Endo, and $60 \%$ for ExoLaw (see Fig.1). This finding is in line with our unconditional democracy hypotheses. The study of Tyran and Feld (2006) is fairly similar and thus allows for some cautious comparisons. One of their major results is that "Efficiency is higher if mild law is endogenously enacted than if it is exogenously enacted". They thereby only focus on the situations when a law is in place. Their figures are: EndoLaw (64\%) to ExoLaw (38\%) compared to EndoLaw (59\%) and ExoLaw (60\%) in China. The comparison highlights that especially contributions under ExoLaw in China seem to be distinct from previous results.

Under ExoLaw $48 \%$ of all subjects contribute 10 to the public good compared to $28 \%$ in Endo and $21 \%$ in ExoNoLaw. ${ }^{5}$ In ExoLaw (and Endo2), there is a stronger polarization towards full or zero contribution (compare distribution plots of contributions in Figure A.4). This is in line with rational behavior of subjects, as contributing 7,8 or 9 tokens yields lower returns than contributing 10 tokens. It is further intuitive that yes-voters are those who generally contributed more in the unconditional contribution decision in round one (5.9 for yes-voters vs. 4.1 novoters). There are no differences between treatments for the lower end of the distribution. Under

\footnotetext{
${ }^{4}$ The law, the voting procedure, and some details of Sutter, Haigner, and Kocher (2010) and Dal Bó, Foster, and Putterman (2010) differ from the study of Tyran and Feld (2006) and our study. Both Sutter et al. (2010) and Dal Bo et al. (2010) use multiple rounds where learning might play a role. Dal Bo et al. analyze the first round, which does not differ from the multiple rounds. Also, in Dal Bó, Foster, and Putterman's study (2010), the purpose of the tax was to move from a game with one Nash equilibrium to two, while in Sutter et al. (2010) the implemented mild law is non-deterrent, as in Tyran and Feld (2006). However, they use peer punishment and the voting stage differs from Tyran and Feld (2006).

${ }^{5}$ In the following, we focus on actual cooperation levels instead of binary rule compliance. However, our subsequent analysis also holds for rule compliance. We also do not focus on efficiency but on cooperation. Efficiency does not differ between the treatments: ExoLaw 12.0, ExoNoLaw 12.35 and EndoLaw 12.2.
} 
ExoLaw, $26 \%$ of all subjects contribute nothing to the public good, compared to $25 \%$ in Endo and $22 \%$ in ExoNoLaw.

Furthermore, we clearly see that the worker and student samples' absolute values differ considerably: Independent from the treatment, workers consistently show higher contribution levels, with high significance. The worker sample has a contribution rate of $74 \%$ in ExoLaw, 64 $\%$ in ExoNoLaw, and $63 \%$ with Endo. The student sample has a contribution rate of $45 \%$ in ExoLaw, $29 \%$ in ExoNoLaw, and $37 \%$ with Endo. We can safely surmise that this largely reflects the previously described fact that workers are selected from pre-existing teams and therefore activate a shared experience of cooperation. Yet, there is a striking difference between the two samples in the relative treatment effects. The student and worker samples differ significantly in the dimension of authoritarian values (Table II) which have been fostered by the paternalistic authoritarian corporate culture of Fuxing Company. Although we find similar effects in each of these samples (ExoLaw>Endo) we also observe a positive effect of the Endo regime compared to the ExoNoLaw regime (t-value 2.70) for students, while we do not observe any effect for workers (see supplementary appendix 1.3). This already seems to give some suggestive evidence for our conditional democracy hypothesis since contribution to Endo is higher for students who, on average, have lower personal values of obeying authorities than workers.

\section{(insert FIGURE I here)}

\subsection{Causal comparison of top-down and bottom-up procedures}

Our major descriptive result for the pooled Chinese sample is that, exogenously imposed non-deterrent law significantly increases contribution levels compared to a situation without law (t-value 5.56) and that cooperation is significantly higher under ExoLaw than under Endo (t-value 4.20). This is in line with our unconditional democracy hypothesis. However, in this subsection 
we give a more causal interpretation of how a certain voter type would behave under both regimes (more formal details on the identification can also be found in the online appendix). The logic of the identification strategy follows Dal Bó, Foster, and Putterman (2010) and not Tyran and Feld (2006) who focus more on the rule effect within a certain regime.

Since the information effect is essentially zero (or very close to it), it is more straightforward to infer the democracy effect. ${ }^{6}$ We differentiate between situations when the rule is not implemented (ExoNoLaw vs. Endo0) and one effect when the rule is implemented (ExoLaw vs. Endo2). It is central to our approach that in both regimes laws are sometimes implemented and sometimes they are not. This is an inherent feature of democratic choice. The democracy effect is then a weighted combination of these two effects based on actual election results:

- Without implementation of the law (i.e., 0 or 1 group members voted for the law):

Democracy Effect No Law $(\mathrm{DENL})=$ Endo0 - ExoNoLaw

- With implementation of the law (i.e., 2 or 3 group members voted for the law):

Democracy Effect Law $(\mathrm{DEL})=$ Endo2 - ExoLaw

The two effects are shown separately for Yes and No voters in Table III because different (intrinsic) motivations to contribute are based on whether the rule contradicts or corresponds to the preferences of participants. We can see that there is only a positive democracy effect for Yes voters and it occurs when the rule is implemented $\left(0.52^{*}\right.$, t-value 1.67$)$. The positive effect most likely stems from people feeling more self-determined, motivated, and satisfied through

\footnotetext{
${ }^{6}$ There is additional information revealed through the election process because individuals make their decisions contingent on their peers' agreement (information effect). Voting might signal the cooperativeness of a person and thus provides additional information which might influence the democracy premium (i.e. the premium comes from information and not the institution per se). For rule supporters it does not make a difference for implementation of the law whether one or two co-players vote in favor of the law. In both cases, the law will be implemented - but the information content is different. Therefore, we compare Endo1 and Endo2 for supporters. Analogously, we compare EndoO and Endol for opponents/non-supporters. In both cases, contribution differences are below 1 percentage point and clearly insignificant (Table III). Similar to Dal Bó, Foster, and Putterman (2010), we find no information effect in the Endo regime.
} 
democratic participation or as "winners" of the election. However, in the three other cases the democracy effects are negative. There is a negative (insignificant) premium for No voters when the rule is implemented in democratic elections $(-0.47$, $t$-value -1.49$)$, meaning that Chinese participants are not more likely to bow to the majority and cooperate when the law is democratically implemented compared to a situation when the law is exogenously imposed. While the comparisons when the law is implemented might seem more natural, one cannot neglect that there are also cases when a law is not implemented in democratic elections, which might also alter an individual's motivation. Thus, if the aim is to compare democratic to nondemocratic regimes it is important to account for situations when the law is not implemented. We further find a strong negative premium for yes-voters when the law is not implemented in democratic elections $(-1.63 * * *$, $\mathrm{t}$-value -4.45$)$ and a weaker but significant effect for no-voters when the rule is not implemented $\left(-0.43^{* * *}\right.$, t-value -2.39$)$.

Aggregating over the two voter types, we obtain a negative and insignificant democracy premium when the rule is implemented (contribution difference: -0.06) and a large and significantly negative democracy effect when the rule is not implemented (contribution difference: $-0.94 * * *)$. Weighting those two effects with the actual number of cases where the rule is endogenously implemented (37 out of 100) yields the average democracy effect for our sample with a contribution difference of $-0.61 * * *$. We can now generalize our results and simulate the average democracy effect for an alternative share of Yes voters. The higher the share of Yes voters, the more we converge to the positive democracy effect for Yes voters under implementation. Our simulation shows that with a share between 64 and $65 \%$ Yes voter types, we would reach a positive average democracy effect. The share needed for a significantly positive democracy effect would be even higher. However, having no democracy premium in China does not mean, that there is no contribution-increasing effect of democratically enacting a law as 
shown by Tyran and Feld (2006). Especially, we have seen that yes-voters react strongly on whether there is a law (Endo2) or not $($ Endo0 $){ }^{7}$

\section{(insert Table III here)}

\subsection{Top-down policies and societal values in China}

In the previous section, we revealed that ExoLaw leads to the highest contributions in China both for students and workers. Thus, what makes exogenous law so effective in the Chinese context? Our conditional democracy hypothesis is that cultural factors might lead to the high cooperation under top-down implementation, especially values that are congruent with the imposition of rules. Since many things differ between China and Europe or the US it would not be convincing to attribute any difference between these countries to one specific value or norm. Therefore, our following approach to demonstrate that authoritarian values are catalysts to the performance of ExoLaw does not build on cross-country comparisons such as those by Henrich et al. (2005) or Herrmann, Thöni, and Gächter (2008) who had access to subject pools in many different countries. Instead, our main focus of the paper is to relate behavior in the experiment to individual values. Table IV shows a regression of the contribution difference (Contrib. ExoLaw Contrib. Endo) on different socio-demographic variables, cultural factors, and player types for each subject of the experiment.

The factor "obey authority" is the most important and highly significant explanatory for the superiority of the exogenous law and is robust in both subsamples. This finding confirms our conjecture on the importance of congruence in values and rules. Someone who accepts authorities and top down leadership might feel an imposed law more appropriate than a democratically

\footnotetext{
${ }^{7}$ This difference is mainly due to the fact that contributions are low under Endo0. Yet, our aim is to directly compare bottom-up (Endo) to top-down policies (Exo) controlling for the law and not to compare the effect of a law within a certain institution. After all, low contributions under EndoO would increase the democracy effect using such a comparison - although it is clearly a disadvantage of democracies if people do not cooperate when a law is not enacted.
} 
elected law. According to our estimates, a change of one standard deviation in the factor "obey authority" changes the performance of Endo relative to ExoLaw by approximately 1 contribution point $(10 \%$ of the endowment). Being a "free-rider" significantly increases obedience to exogenous law in the worker sample. All socio-demographic variables and value variables except "obey authority" remain insignificant. ${ }^{8}$

One possible concern could be that the subjects did not understand part of the experiment. A straightforward analysis is to exclude those participants who showed apparently irrational behavior. For example, when introducing the sanction, participants should not contribute 7,8 , or 9 tokens to the public good since this will make them worse off than contributing 10 (and avoiding the sanction). The last regression in Table IV also confirms our results excluding the subsample of irrational subjects $(\mathrm{n}=30)$.

However, most importantly for robustness analysis, student and worker samples show similar relative effects: In both samples, ExoLaw is clearly fostering cooperation. In addition, the main result that "obey authorities" explains the differences in ExoLaw-Endo (see Table IV) for each sample.

\section{（insert Table IV here）}

To further analyze the relevance of the effect, we split the sample in "low obey" (obey authority factor below average) and "high obey" (obey authority factor above average). In both subsamples, we compare the performance of ExoNoLaw, Endo, and ExoLaw. Interestingly, in the low obey sample, ExoLaw is insignificant from Endo (t-value -0.36) and only slightly better than

\footnotetext{
${ }^{8}$ In our regression and in general, we do not find that conditional cooperators react differently. One might have expected that participants' beliefs about the other participants' contributions drive the democracy effect (i.e., through information). One would expect conditional cooperators to more readily react to information signals of the voting behaviors of others. However, we do not find that conditional cooperators increase contributions in the endogenous treatment. This insignificance of conditional cooperator in reacting on information is in line with our previous observation that the information effect is close to zero. Further analysis shows that the information effect is small and insignificant also in the subset of conditional cooperators (results available upon request).
} 
ExoNoLaw (t-value 1.91). In contrast in the high obey sample, ExoLaw clearly leads to higher contributions, and there is not even a significant difference between endogenous rule and no law (t-value Endo vs. ExoLaw -5.30, Endo vs. ExoNoLaw 0.24; see online appendix for additional figures and tables).

We repeat the decomposition of contributions by voter type in Table V below for both the low obey $(n=132)$ and the high obey $(n=167)$ subsamples. In line with the meaning of the value of obeying, we find that both those who like the law and those who do not like the law react to the exogenous implementation in the high obey sample (contribution difference ExoLaw vs. ExoNoLaw is on average $1.77^{* * *}$ for No and $1.76^{* * *}$ for Yes voters). Interestingly, in the low obey sample, only those who prefer the law also react to an exogenous introduction, and the reaction is more moderate than for the high obey sample (contribution difference ExoLaw vs. ExoNoLaw is on average 0.18 for No voters and 1.46 for Yes voters).

The findings on "obey authorities" or "acceptance of authority" can further be substantiated by the fact that there is no positive democracy effect in the high obey sample, not even for the Yes voter when the rule is implemented. In contrast, in the low obey sample, Yes voters have a positive and strong democracy effect under rule implementation $\left(1.40^{* *}\right){ }^{9}$

\section{(Insert Table V here)}

\subsection{Societal values determine crowding-out effects of intrinsic motivation}

\footnotetext{
${ }^{9}$ Nevertheless, the strong negative democracy effect for Yes voters when the rule is not implemented remains large and negatively significant in both the high and low obey samples. This means that Yes voters from the low obey sample act like "opportunistic democrats" in the sense that they only cooperate more after a favorable election outcome. We also ran regressions including control variables similar to the one in Table IV, using (ExoLaw-Endo2) (NoLaw-Endo0) instead of (ExoLaw-Endo) as the dependent variable. Our results show that "high Obey" is mainly significant in the (ExoLaw-Endo2) specification for Yes voters, i.e., under implementation. This means the positive democracy effect is missing for those with high values of obeying authority. All these effects can be seen even more clearly in Table $\mathrm{V}$, which shows the composition of the democracy effect by high/low obey.
} 
The democracy premium in previous experiments in Western societies is closely linked to the presence of crowding-out effects (for exogenous law) or crowding-in effects (for endogenous law). The imposition of a fine has been used as the standard showcase where the crowding-out effect emerges (Gneezy and Rustichini, 2000). Self-determination and autonomy are congruent with endogenous rule procedures and thus we expect that in our sample of low obey subjects, we observe more crowding-out effects for exogenous institutions. To apply this hypothesis to our set-up, we define a dummy called "crowding-out" that is equal to one if contributions under ExoLaw are lower than under ExoNoLaw.

Table VI features a probit regression using the same covariate specification as in Table IV and our dummy for "crowding-out" as the outcome variable. It shows that crowding-out behavior is more prevalent amongst those with lower values of accepting authorities. This factor is the most significant amongst all covariates and the only one that is significant across all specifications and subsamples. Furthermore, higher educated people are also more likely to lose their intrinsic motivations due to an imposed law, and free-riders are less likely to do so.

\section{(insert Table VI here)}

\section{Conclusion}

Overcoming social dilemmas by achieving high rates of cooperation is required for the proper functioning of groups, organizations, and society as a whole. One prominent proposition to enhance cooperation among citizens, even in larger groups, is to hold democratic elections. In the case of China, we find that democratic rule choice not necessarily leads to superior outcomes.

First, in line with our unconditional democracy hypotheses, we find that participants cooperate the most with an exogenously imposed law. Furthermore, controlling for rule implementation, average contributions for non-democratic regimes are higher than those with 
democratic regimes. Second, and in line with our conditional democracy hypotheses, we find that this effect is stronger for the worker sample which has higher values for accepting authorities. The student sample with lower values of accepting authorities (but similar values in e.g. collectivism) has some positive effect of endogenous choice and thereby comes closer to the results in western countries. Third, we further substantiate our evidence for the conditional democracy hypotheses. We find a strong positive correlation between the effectiveness of exogenous top-down implementation and high values of accepting authorities at the individual level for both students and workers. For people with weaker norms of accepting authorities, we find a positive significant democracy effect for Yes voters when the rule is implemented. In addition, people with weaker norms of accepting authorities do not comply with a top-down policy when they do not like the rule. People with stronger norms of accepting authorities obey strongly to the exogenous law and cooperate regardless of whether they like the rule or not. Thus, these findings suggest that authoritarian norms bolster the effectiveness of top-down policies.

Behavioral differences between Chinese and western subjects are not surprising. They are in line with psychological cross-cultural experiments (Iyengar and Lepper, 1999) and more recent experiments with Asian Americans living in the United States that have shown remarkable differences dependent on which social identity (Chinese or American) happened to be salient at the moment of choice. With Chinese identity being salient subjects behaved more collectivistic (LeBoeuf, Shafir and Belyavsky Bayuk 2010) or more patient (Benjamin, Choi and Strickland 2010). Besides being collectivistic and long-term oriented, accepting authorities and inequality in hierarchies is a distinct cultural norm that correlates with Chinese societies (Hofstede, Hofstede and Minkov 2010; Inglehart and Welzel 2005; House et al. 2004). We could show that this prominent cultural norm in the Chinese context has important implications for policy making. We argue that formal institutions such as democratic elections need to be aligned with underlying 
supportive informal institutions in order to gain legitimacy and best possible outcomes. Thus, institutions should not be implemented without considering the broader context or local norms (Ostrom, Janssen and Anderies 2007).

Our results do not suggest an inevitably long-run effect of a cultural legacy on current practices (more so since we do not allow for learning effects in our experiment) ${ }^{10}$ nor should results be misinterpreted as implying that democracy in China does not work. The political and economic literature on the effects of democracy highlights two major benefits besides the discussed "democracy premium" for cooperation among citizens: accountability of politicians through looming re-election (Barro 1973) and selection of more honest and competent politicians (Besley 2005), leading to more equitable, pro-poor, and efficient provision of public goods (Sen 1981; Deacon 2009). More recently Corazzini et al. (2014) showed that democratically elected leaders are more likely to stick to non-binding campaign promises. Such positive findings on the behavior of politicians are also reported from village elections in China (Zhang et al. 2004; Wang and Yao 2007; Martinez-Bravo et al. 2012). However, it seems that these new democratic practices slowly change the value system. Shi (2000) analyzed values towards democracy in China and found that the power and authority values of people living in areas where these "semicompetitive local elections" were held have not yet changed.

Our study adds to the existing evidence of cultural differences between China and western societies by showing its implications for policy making -and not only highlighting cultural differences. We argue that congruence of values, norms, and rules is important to gain legitimacy of governance regimes. The results of our study allow for some cautious policy implications.

\footnotetext{
${ }^{10}$ Consistent with theories that posit education is the foremost driver for political change, we also find a less negative democracy premium in the student sample and that students in general have weaker norms of obeying authorities. Similarly, in many Western countries, with the emergence of a politically powerful middle class and/or the introduction of democracy, the power of authorities has been progressively eroded and self-expression values became more widespread (e.g. in Germany or Japan after World War II). Also, the example of Taiwan highlights that with a real "big push," a well-functioning democracy can be established in a Chinese cultural context.
} 
From our combined findings, it is evident that the democratic transformation of societies is barely achieved by holding democratic elections. Policies that change underlying societal values are more important for a functioning democracy. 


\section{REFERENCES}

Alm, James, Gary H. McClelland, and William D. Schulze. 1999. "Changing the social norm of tax compliance by voting." Kyklos 52 (2):141-71.

Altemeyer, Bob. 1988. "Enemies of freedom: Understanding right-wing authoritarianism" The Jossey-Bass social and behavioral science series and The Jossey-Bass public administration series, San Francisco

Bardhan, P. 2000. "Irrigation and cooperation: An empirical analysis of 48 irrigation communities in South India." Economic Development and Cultural Change 48 (4):847-65.

Barro, Robert J. 1973. "The control of politicians: an economic model." Public Choice 14 (1):1942.

1999. "Determinants of democracy." Journal of Political Economy 107 (6):158-83.

Benjamin, Daniel J., James J. Choi, and A. Joshua Strickland. 2010. "Social Identity and Preferences." American Economic Review, 100 (4): 1913-28.

Besley, Timothy. 2005. "Political selection." Journal of Economic Perspectives 19 (3):43-60.

Bowles, Samuel. 1998 "Endogenous Preferences: The Cultural Consequences of Markets and other Economic Institutions" Journal of Economic Literature 36:75-111.

2008. "Policies designed for self-interested citizens may undermine "the moral sentiments": evidence from economic experiments." Science (New York, N.Y.) 320:1605-9.

Cameron, Lisa, Ananish Chaudhuri, Nisvan Erkal, and Lata Gangadharan. 2009. "Do Attitudes Towards Corruption Differ Across Cultures? Experimental Evidence from Australia, India, Indonesia and Singapore." Journal of Public Economics 93:843-51.

Cameron, Lisa, Nisvan Erkal, Lata Gangadharan, and Xin Meng. 2013. "Little emperors: behavioral impacts of China's One-Child Policy." Science (New York, N.Y.) 339 (6122):9537. 
Casey, Katherine, Rachel Glennerster, and Edward Miguel. 2012. "Reshaping Institutions: Evidence on Aid Impacts Using a Preanalysis Plan." Quarterly Journal of Economics 127 (4):1755-812.

Chen, Chao C., and Jiing-lih Farh. 2010. "Developments in understanding Chinese leadership: paternalism and its elaborations, moderations, and alternatives." In The Oxford Handbook of Chinese Psychology. Oxford: Oxford University Press.

Corazzini, Luca, Sebastian Kube, Michel André Maréchal, and Antonio Nicolò. 2014. "Elections and Deceptions: An Experimental Study on the Behavioral Effects of Democracy." American Journal of Political Science 58 (3):579-92.

Dal Bó, Pedro, Andrew Foster, and Louis Putterman. 2010. "Institutions and Behavior: Experimental Evidence on the Effects of Democracy." American Economic Review 100 (5):2205-29.

Deacon, Robert T. 2009. "Public good provision under dictatorship and democracy." Public Choice 139 (1-2):241-62.

Deci, Edward L., Richard Koestner, and Richard M. Ryan. 1999. "A meta-analytic review of experiments examining the effects of extrinsic rewards on intrinsic motivation." Psychological Bulletin 125 (6):627.

Decker, Torsten, Andreas Stiehler, and Martin Strobel. 2003. "A comparison of punishment rules in repeated public good games - An experimental study." Journal of Conflict Resolution 47 (6):751-72.

Duckitt, John, and Chris G. Sibley. 2010. "Right-Wing Authoritarianism and Social Dominance Orientation differentially moderate intergroup effects on prejudice." European Journal of Personality 24 (7):583-601. 
Ertan, Arhan, Talbot Page, and Louis Putterman. 2009. "Who to punish? Individual decisions and majority rule in mitigating the free rider problem." European Economic Review 53 (5):495511.

Farh, Jiing-Lih, Jian Liang, Li-fang Chou, and Bor-shiuan Cheng. 2008. "Paternalistic leadership in Chinese organizations: Research progress and future research directions." In Leadership and Management in China, Cambridge: Cambridge University Press.

Feldman, Stanley. 2003. "Enforcing social conformity: A theory of authoritarianism." Political Psychology 24 (1):41-74.

Fischbacher, Urs, Simon Gächter, and Ernst Fehr. 2001. "Are people conditionally cooperative? Evidence from a public goods experiment." Economics Letters 71 (3):397-404.

Foels, Rob, James E. Driskell, Brian Mullen, and Eduardo Salas. 2000. "The effects of democratic leadership on group member satisfaction an integration." Small Group Research $31(6): 676-701$.

Frey, Bruno S., and Felix Oberholzer-Gee. 1997. "The cost of price incentives: An empirical analysis of motivation crowding-out." American Economic Review 87 (4):746-55.

Galbiati, Roberto, and Pietro Vertova. 2008. "Obligations and cooperative behaviour in public good games." Games and Economic Behavior 64 (1):146-70.

Gneezy, Uri, and Aldo Rustichini. 2000. “A Fine Is a Price.” The Journal of Legal Studies 29 (1) $1-17$.

Hay, Jonathan R., Andrei Shleifer, and Robert W. Vishny. 1996 "Toward a Theory of Legal Reform," European Economic Review, 40(3): 559-567.

Henrich, Joseph, Robert Boyd, Samuel Bowles, Colin F Camerer, Ernst Fehr, Herbert Gintis, Richard McElreath, Michael S Alvard, Abigail Barr, Jean Ensminger, Natalie Smith Henrich, Kim Hill, Francisco Gil-White, Michael Gurven, Frank W Marlowe, John Q Patton, and 
David P Tracer. 2005. "'Economic man" in cross-cultural perspective: behavioral experiments in 15 small-scale societies." Behavioral and Brain Sciences 28:795-815; discussion -55 .

Herrmann, Benedikt, Christian Thöni, and Simon Gächter. 2008. "Antisocial Punishment across Societies." Science 319 (5868):1362-7.

Hofstede, Geert, Gert Jan Hofstede, and Michael Minkov. 2010. "Cultures and Organizations: Software of the Mind, Third Edition" McGraw-Hill Education.

House, Robert J., Paul J. Hanges, Mansour Javidan, Peter W. Dorfman, and Vipin Gupta. 2004. "Culture, leadership, and organizations" Sage Publications, London.

Ichniowski, Casey, and Kathryn Shaw. 2003. "Beyond incentive pay: Insiders' estimates of the value of complementary human resource management practices." Journal of Economic Perspectives 17 (1):155-80.

Inglehart, Ronald and Christian Welzel. 2005. "Modernization, cultural change, and democracy: The human development sequence" Cambridge University Press.

Iyengar, Sheena S, and Mark R Lepper. 1999. "Rethinking the value of choice: a cultural perspective on intrinsic motivation." Journal of Personality and Social Psychology 76 (3):349.

Kamei, Kenju, Louis Putterman, and Jean-Robert Tyran. 2015. "State or nature? Endogenous formal versus informal sanctions in the voluntary provision of public goods" Experimentl Economics 18 (1):38-65.

Kocher, Martin G., Todd Cherry, Stephan Kroll, Robert J. Netzer, and Matthias Sutter. 2008. "Conditional cooperation on three continents." Economics Letters 101 (3):175-8. 
Kube, Sebastian, Sebastian Schaube, Hannah Schildberg-Hörisch, and Elina Khachatryan. 2014. „Institution Formation and Cooperation with Heterogeneous Agents.” IZA Discussion Paper No. 8533

Kulich, Steve J., and Rui Zhang. 2010. "The multiple frames of "Chinese" values: from tradition to modernity and beyond." In The Oxford Handbook of Chinese Psychology:241-78.

Martinez-Bravo, Monica, Gerard Padro, Nancy Qian and Yang Yao 2012. "The Effects of Democratization on Public Goods and Redistribution: Evidence from China." CEPR Discussion Papers 8975.

LeBoeuf, Robyn A., Eldar Shafir, and Julia Belyavsky Bayuk. 2010. "The conflicting choices of alternating selves." Organizational Behavior and Human Decision Processes 111 (1):48-61.

Lipset, Seymour Martin. 1959. "Some social requisites of democracy: Economic development and political legitimacy." The American Political Science Review:69-105.

Liu, James H, Mei-chih Li, and Xiaodong Yue. 2010. "Chinese social identity and inter-group relations: the influence of benevolent authority." The Oxford Handbook of Chinese Psychology:579-97.

Markussen, Thomas, Louis Putterman, and Jean-Robert Tyran. 2014. "Self-organization for collective action: An experimental study of voting on sanction regimes." The Review of Economic Studies 81 (1):301-24.

Mazar, Nina, and Dan Ariely. 2006. "Dishonesty in everyday life and its policy implications." Journal of Public Policy \& Marketing:1 17-26.

Naditch, Murray P. 1974. "Locus of control, relative discontent and hypertension." Social Psychiatry and Psychiatric Epidemiology 9 (3):111-7.

North, Douglass C. 1990. "Institutions, institutional change and economic performance". Cambridge university press, New York. 
North, Douglass C. 1993. "Prize Lecture: "Economic Performance through Time"'”. Available from: $\quad$ http://www.nobelprize.org/nobel_prizes/economic-sciences/laureates/1993/northlecture.html (accessed: November $\left.23^{\text {rd }} 2013\right)$.

Olken, Benjamin A. 2010. "Direct Democracy and Local Public Goods: Evidence from a Field Experiment in Indonesia." American Political Science Review 104 (2):243-67.

Ostrom, Elinor. 2000. "Collective Action and the Evolution of Social Norms." Journal of Economic Perspectives 14 (3):137-58.

Ostrom, Elinor, Marco A. Janssen, and John M. Anderies. 2007. "Going beyond panaceas." Proceedings of the National Academy of Sciences 104 (39):15176-8.

Ostrom, Elinor, James Walker, and Roy Gardner. 1992. "Covenants with and without a sword: Self-governance is possible." The American Political Science Review:404-17.

Pommerehne, Werner W., and Hannelore Weck-Hannemann. 1996. "Tax rates, tax administration and income tax evasion in Switzerland." Public Choice 88 (1-2):161-70.

Posner, Eric A. 1998. "Symbols, signals, and social norms in politics and the law." The Journal of Legal Studies 27 (2):765-97.

Sen, Amartya. 1981. "Poverty and Famines: An Essay on Entitlement and Deprivation" Oxford University Press.

Shavitt, Sharon, Jing Zhang, Carlos J. Torelli, and Ashok K. Lalwani. 2006. "Reflections on the meaning and structure of the horizontal/vertical distinction." Journal of Consumer Psychology 16 (4):357-62.

Shi, Tianjian. 2000. "Cultural values and democracy in the People's Republic of China." China Quarterly:540-59.

Sunstein, Cass R. 1996. "On the expressive function of law." University of Pennsylvania Law Review 144 (5):2021-53. 
Sutter, Matthias, Stefan Haigner, and Martin G. Kocher. 2010. "Choosing the Carrot or the Stick? Endogenous Institutional Choice in Social Dilemma Situations." Review of Economic Studies 77 (4):1540-66.

Torelli, Carlos J., and Sharon Shavitt. 2010. "Culture and concepts of power." Journal of Personality and Social Psychology 99 (4):703.

Triandis, Harry C., and Michele J. Gelfand. 1998. "Converging measurement of horizontal and vertical individualism and collectivism." Journal of Personality and Social Psychology 74 (1):118-28.

Tyran, Jean R., and Lars P. Feld. 2006. "Achieving compliance when legal sanctions are nondeterrent." Scandinavian Journal of Economics 108 (1):135-56.

Walker, James M., Roy Gardner, Andrew Herr, and Elinor Ostrom. 2001. "Collective choice in the commons: Experimental results on proposed allocation rules and votes." The Economic Journal 110 (460):212-34.

Wang, Shuna, and Yang Yao. 2007. "Grassroots democracy and local governance: Evidence from rural China." World Development 35 (10):1635-49.

Weber, Max (1968). Economy and society: Part I and II. Berkeley: The University of California Press.

Zhang, Xiaobo, Shenggen. Fan, Linxiu. Zhang, and Jikun Huang. 2004. "Local governance and public goods provision in rural China." Journal of Public Economics 88 (12):2857-71.

Zwick, Thomas 2004. "Employee participation and productivity." Labour Economics 11 (6):71540. 


\section{FIGURES}

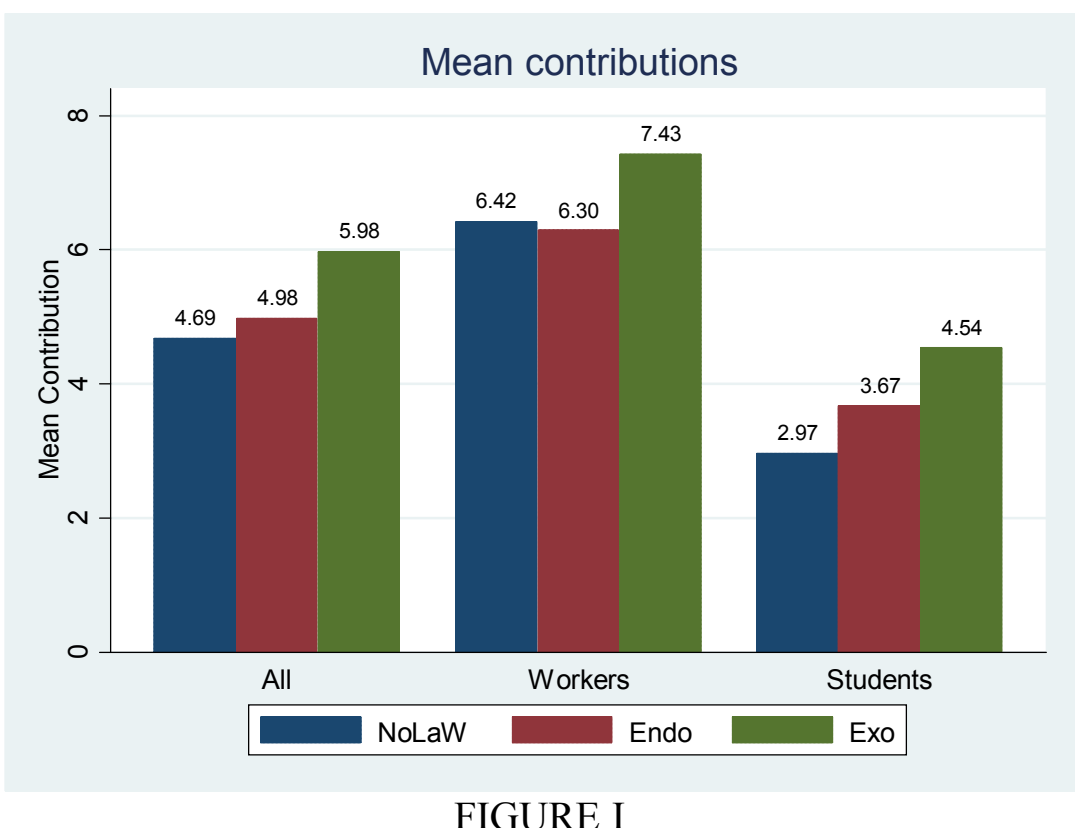

Mean Contribution in the pooled sample using actual voting outcomes $(n=299)$

The difference ExoLaw vs ExoNoLaw (1.29, t-value 5.56***) and Endo vs ExoLaw (-1.00, t-value -4.21***) are highly significant while the difference between Endo vs ExoNoLaw (0.29, t-value 1.31) is insignificant. 


\section{TABLES}

TABLE I

Contributions measured in one-shot public good games under different regimes and rule implementations

\begin{tabular}{lcc}
\hline \hline & Available for: \\
& \multicolumn{2}{c}{$\begin{array}{c}\text { Student sample }(\mathrm{n}=150) \\
\text { Worker sample (n=149) }\end{array}$} \\
\cline { 2 - 3 } & No law implemented & Mild law implemented \\
\hline Exogenous imposed (top-down) & ExoNoLaw & ExoLaw \\
Endogenously chosen (voted) & Endo0, (Endo1) & (Endo1), Endo2 \\
\hline \hline
\end{tabular}

Note. The benchmark case is the ExoNoLaw case: There is no law, and the participants cannot vote to apply a punishment. This differs from the setting where participants vote to reject a rule that applies a punishment (Endo0). Next we distinguish between the setting where a punishment rule is imposed by the experimenter (ExoLaw) and where the participants vote in favour of such a rule (Endo2). In Endo1 it depends on the person being a Yes or No voter whether the rule will be implemented or not. The complete treatment plan is provided in the online appendix in Table A1. 
TABLE II

Major characteristics of the student and worker sample

\begin{tabular}{|c|c|c|c|c|c|}
\hline & \multicolumn{2}{|c|}{ Mean Value } & \multirow[t]{2}{*}{ T-Value } & \multicolumn{2}{|c|}{ Numbers of } \\
\hline & Students & Workers & & Students & Workers \\
\hline & \multicolumn{5}{|c|}{ Demographics } \\
\hline Age & 21.71 & 33.96 & $-17.17 * * *$ & 150 & 144 \\
\hline Gender $^{\mathrm{a}}$ & 1.68 & 1.20 & $8.36 * * *$ & 150 & 147 \\
\hline Education $^{\mathrm{b}}$ & 6.37 & 3.23 & $28.15 * * *$ & 150 & 149 \\
\hline Income $e^{c}$ & 381 & 2266 & $-20.11 * * *$ & $81^{\mathrm{g}}$ & 143 \\
\hline Owe $e^{d}$ & 0.07 & 0.24 & $-4.17 * * *$ & 150 & 145 \\
\hline Life satisfaction ${ }^{\mathrm{e}}$ & 5.95 & 5.97 & -0.11 & 149 & 149 \\
\hline Willingness to take Risk $^{\mathrm{f}}$ & 4.68 & 5.04 & -1.45 & 149 & 149 \\
\hline \multicolumn{6}{|l|}{ Factors } \\
\hline Obey authority & -0.46 & 0.49 & $-9.14 * * *$ & 147 & 138 \\
\hline Demand of punish & 0.07 & -0.08 & 1.25 & 147 & 138 \\
\hline Locus of control & 0.06 & -0.06 & 0.99 & 148 & 141 \\
\hline Collectivism & 0.04 & -0.04 & 0.61 & 148 & 140 \\
\hline Competitiveness & -0.16 & 0.17 & $-2.89 * * *$ & 148 & 140 \\
\hline \multicolumn{6}{|l|}{ Cooperation type } \\
\hline Conditional cooperator & 0.47 & 0.51 & -0.63 & 150 & 149 \\
\hline Freerider & 0.14 & 0.05 & $2.76 * * *$ & 150 & 149 \\
\hline Other & 0.32 & 0.34 & -0.41 & 150 & 149 \\
\hline Altruist & 0.01 & 0.07 & $-2.95 * * *$ & 150 & 149 \\
\hline Triangle & 0.06 & 0.03 & 1.40 & 150 & 149 \\
\hline \multicolumn{6}{|c|}{$\begin{array}{l}\text { Note. Significance levels: } * \mathrm{p}<0.1, * * \mathrm{p}<0.05, * * * \mathrm{p}<0.01 \text {. Comparative summary of major characteristics of the } \\
\text { student and worker sample according to three different classes: socio-demographic properties; attitudes and values as } \\
\text { extracted from a set of attitudinal questions by means of factor analysis; types of players as determined by running a } \\
\text { first experimental round asking the subjects to make conditional or unconditional contributions. Note: a) Men =1 } \\
\text { Women=2; b) } 1=\text { Elementary, } 2=\text { Junior High School, } 3=\text { Senior High School, } 4=\text { Open University, } 5=\text { associate } \\
\text { degree(full-time), } 6=\text { Bachelor Degree(full-time), } 7=\text { Master's Degree(full-time); c) Yuan per month; d) owe money, } \\
\text { labor with a value higher than } 1000 \text { Yuan } 0=\text { No, } 1=\text { Yes; e) 9-point scale , } 1 \text { (worst possible life) to } 9 \text { (best possible } \\
\text { life); f) 9-point scale, } 1 \text { (not willing to take risk) to } 9 \text { (highly willing to take risk); g) As most missing value of } \\
\text { students' income actually should be } 0 \text {, this mean for students is much overestimated. }\end{array}$} \\
\hline
\end{tabular}


TABLE III

Descriptive Analysis between treatments and for the full sample between Yes voters $(n=126)$ and No-voters $(n=173)$

\begin{tabular}{|c|c|c|c|}
\hline & \multicolumn{2}{|c|}{ Mean contribution } & \multirow{2}{*}{$\begin{array}{c}\text { Mean difference } \\
\text { between No and Yes Voter }\end{array}$} \\
\hline & No voter & Yes voter & \\
\hline Contrib. ExoNoLaw & 3.80 & 5.92 & $-2.12 * * *$ \\
\hline Contrib. Endo & 3.58 & 6.90 & $-3.32 * * *$ \\
\hline Contrib. ExoLaw & 4.83 & 7.56 & $-2.72 * * *$ \\
\hline Contrib. Endo0 & 3.36 & 4.29 & $-0.92 * *$ \\
\hline Contrib. Endo1 & 3.45 & 8.02 & $-4.57 * * *$ \\
\hline Contrib. Endo2 & 4.36 & 8.07 & $-3.713 * * *$ \\
\hline $\mathrm{N}$ & 173 & 126 & \\
\hline \multicolumn{4}{|c|}{ Mean difference } \\
\hline ExoLaw vs ExoNoLaw & $1.03 * * *$ & $1.63 * * *$ & \\
\hline Endo vs ExoLaw & $-1.25 * * *$ & -0.65 & \\
\hline Endo vs ExoNoLaw & -0.21 & $.98 * *$ & \\
\hline Endo0 vs Endo1 & $-.08 \mathrm{IE}$ & $-3.73 * * *$ & \\
\hline Endo1 vs Endo2 & $-0.91 * * *$ & $-0.06 \mathrm{IE}$ & \\
\hline Endo0 vs ExoNoLaw & $-0.43 * *$ DENL & $-1.63 * * *$ DENL & \\
\hline Endo2 vs ExoLaw & $-0.47 \mathrm{DEL}$ & $0.52 * \mathrm{DEL}$ & \\
\hline
\end{tabular}

Note. The upper panel shows mean contribution for Yes- and No-voters and their mean difference stared with corresponding t-values (two-sided t-test). Generally, Yes voters make higher contributions irrespective of the treatment. The lower panel displays t-values separated for yes and no voters for all possible treatment combinations. We identify the two information effects (IE) as being insignificant. The two democracy effects when law is not implemented (DENL) are negative significant both for Yes and No voters. The democracy effects when law is implemented (DEL) is positive significant $(10 \%)$ for the Yes voters and negative but insignificant for No-voters. 
TABLE IV

OLS regression with robust standard errors explaining differences in contribution levels between exogenous and endogenous treatment for the pooled sample and each subsample as well as excluding irrational participants.

\begin{tabular}{|c|c|c|c|c|c|c|c|c|c|c|}
\hline & \multicolumn{2}{|c|}{ All } & \multicolumn{2}{|c|}{ All } & \multicolumn{2}{|c|}{ Students } & \multicolumn{2}{|c|}{ Workers } & \multicolumn{2}{|c|}{ Rational } \\
\hline & coef. & s.e. & coef. & s.e. & coef. & s.e. & coef. & s.e. & coef. & s.e. \\
\hline Student & 0.54 & $(0.56)$ & 0.99 & $(1.06)$ & & & & & 0.59 & $(1.15)$ \\
\hline Age & & & 0.060 & $(0.046)$ & 0.036 & $(0.26)$ & 0.036 & $(0.052)$ & 0.050 & $(0.051)$ \\
\hline Gender & & & 0.56 & $(0.62)$ & 1.02 & $(0.76)$ & -1.03 & (1.18) & 0.55 & $(0.66)$ \\
\hline Education & & & -0.17 & $(0.29)$ & 0.90 & $(0.96)$ & -0.45 & $(0.36)$ & -0.14 & $(0.32)$ \\
\hline Owe money & & & 0.19 & $(0.74)$ & 0.23 & $(1.47)$ & 0.17 & $(0.95)$ & -0.22 & $(0.83)$ \\
\hline Life satisfaction & & & 0.19 & $(0.18)$ & 0.25 & $(0.28)$ & 0.22 & $(0.26)$ & 0.29 & $(0.20)$ \\
\hline Willingness to take risk & & & -0.040 & $(0.14)$ & -0.028 & $(0.21)$ & -0.034 & $(0.19)$ & -0.071 & $(0.15)$ \\
\hline Conditional cooperator & & & 0.66 & $(0.54)$ & 0.23 & $(0.74)$ & 0.94 & $(0.86)$ & 0.68 & $(0.59)$ \\
\hline Free rider & & & -0.075 & $(0.94)$ & -1.46 & $(1.08)$ & $3.68^{*}$ & $(1.92)$ & -0.055 & $(0.98)$ \\
\hline Round 1 contribution & & & -0.11 & $(0.096)$ & -0.044 & $(0.13)$ & -0.12 & $(0.15)$ & -0.12 & $(0.10)$ \\
\hline Obey authority & $0.95^{* * *}$ & $(0.29)$ & $0.95 * * *$ & $(0.30)$ & $0.97 * *$ & $(0.43)$ & $0.94 * *$ & $(0.43)$ & $0.98^{* * *}$ & $(0.32)$ \\
\hline Demand of punish & & & 0.41 & $(0.25)$ & 0.34 & $(0.34)$ & 0.44 & $(0.43)$ & 0.42 & $(0.27)$ \\
\hline Locus of control & & & -0.17 & $(0.27)$ & $-0.78^{*}$ & $(0.40)$ & 0.0065 & $(0.41)$ & -0.29 & $(0.29)$ \\
\hline Collectivism & & & 0.42 & $(0.26)$ & $0.62 *$ & $(0.35)$ & 0.40 & $(0.42)$ & $0.47^{*}$ & $(0.28)$ \\
\hline Competitiveness & & & -0.40 & $(0.26)$ & -0.17 & $(0.37)$ & -0.45 & $(0.40)$ & -0.32 & $(0.29)$ \\
\hline Constant & $0.68^{*}$ & $(0.38)$ & -1.87 & $(2.30)$ & -8.16 & $(5.04)$ & 1.16 & (3.16) & -1.94 & (2.53) \\
\hline $\mathrm{N}$ & 268 & & 268 & & 144 & & 124 & & 241 & \\
\hline
\end{tabular}

Note. Explanatory variables are a dummy for the student sample, socio demographic variables, experimental measures of conditional co-operator and free-rider, and the factors. Rational subjects are those who do respond rationally to the introduction of the sanction. 


\section{TABLE V}

Subsample analysis for below (left) and above (right) average of the factor obey authority, treatments and whether person is Yes or No-voters.

(a)

Democracy effect low obey

\section{Mean contribution}

Contrib. ExoNoLaw

Contrib. Endo

Contrib. ExoLaw

Contrib. Endo0

Contrib. Endo1

Contrib. Endo2

$$
\mathrm{N}
$$

ExoLaw vs ExoNoLaw

Endo vs ExoLaw

Endo vs ExoNoLaw

Endo0 vs ExoNoLaw

Endo2 vs ExoLaw

\section{Yes to rule}

5.75

7.54

7.21

4.02

8.46

8.62
80

52

(b)

Democracy effect high obey

\section{Mean contribution}

\section{No to rule}

4.47

4.28

6.25

3.81

3.89

5.65

93
Yes to rule

6.04

6.46

7.80

4.47

7.70

7.69
74

Note. The upper panel shows mean contribution for Yes- and No-voters. The lower panel displays mean differences stared according to their t-values separated for yes and no voters for the four democracy effects. The information effects are again insignificant (not shown). For the low obey subsample there is a substantial and significantly positive democracy effect for yes voters under law implementation and only the democracy effect under nonimplementation for yes voters is significantly negative. In contrast, all four democracy effects in the high obey subsample are negative, two of them significantly 


\section{TABLE VI}

Marginal effects after probit regression with robust standard errors explaining the dummy

"crowding-out" that is equal to one if contributions under ExoLaw are lower than under

ExoNoLaw treatment for the pooled sample and each subsample as well as excluding irrational

participants.

\begin{tabular}{|c|c|c|c|c|c|c|c|c|c|c|}
\hline & \multicolumn{2}{|c|}{ All } & \multicolumn{2}{|c|}{ All } & \multicolumn{2}{|c|}{ Students } & \multicolumn{2}{|c|}{ Workers } & \multicolumn{2}{|c|}{ Rational } \\
\hline & coef. & s.e. & coef. & s.e. & coef. & s.e. & coef. & s.e. & coef. & s.e. \\
\hline Student & -0.084 & $(0.055)$ & $-0.26^{* *}$ & $(0.10)$ & & & & & $-0.31 * * *$ & $(0.11)$ \\
\hline Age & & & 0.0010 & $(0.0041)$ & 0.023 & $(0.026)$ & 0.0041 & $(0.0042)$ & -0.00032 & $(0.0046)$ \\
\hline Gender & & & 0.042 & $(0.064)$ & 0.025 & $(0.075)$ & $0.18^{*}$ & $(0.097)$ & 0.044 & $(0.066)$ \\
\hline Education & & & $0.055^{* *}$ & $(0.026)$ & -0.087 & $(0.091)$ & $0.077 * * *$ & $(0.028)$ & $0.063^{* *}$ & $(0.029)$ \\
\hline Owe money & & & -0.088 & $(0.056)$ & -0.019 & $(0.13)$ & $-0.13 * *$ & $(0.060)$ & -0.099 & $(0.060)$ \\
\hline Life satisfaction & & & -0.024 & $(0.018)$ & $-0.054^{* *}$ & $(0.027)$ & -0.013 & $(0.025)$ & -0.024 & $(0.019)$ \\
\hline Willingness to take risk & & & 0.017 & $(0.013)$ & $0.038^{*}$ & $(0.020)$ & 0.011 & $(0.017)$ & 0.019 & $(0.014)$ \\
\hline Conditional cooperator & & & $-0.087^{*}$ & $(0.050)$ & $-0.14 * *$ & $(0.066)$ & -0.0089 & $(0.074)$ & $-0.098^{*}$ & $(0.054)$ \\
\hline Free rider & & & $-0.17^{* * *}$ & $(0.040)$ & $-0.20 * * *$ & $(0.045)$ & -0.12 & $(0.079)$ & $-0.19 * * *$ & $(0.040)$ \\
\hline Round 1 contribution & & & -0.0040 & $(0.0086)$ & -0.0076 & $(0.011)$ & 0.0017 & $(0.013)$ & -0.0053 & $(0.0091)$ \\
\hline Obey authority & $-0.098 * * *$ & $(0.030)$ & $-0.096 * * *$ & $(0.028)$ & $-0.085^{* *}$ & $(0.037)$ & $-0.091 * *$ & $(0.040)$ & $-0.096 * * *$ & $(0.030)$ \\
\hline Demand of punish & & & -0.0037 & $(0.022)$ & -0.0099 & $(0.029)$ & -0.012 & $(0.031)$ & -0.0036 & $(0.023)$ \\
\hline Locus of control & & & 0.0027 & $(0.025)$ & 0.039 & $(0.039)$ & -0.0099 & $(0.031)$ & 0.0039 & $(0.026)$ \\
\hline Collectivism & & & 0.0048 & $(0.023)$ & -0.037 & $(0.034)$ & 0.025 & $(0.031)$ & -0.0043 & $(0.024)$ \\
\hline Competitiveness & & & 0.0017 & $(0.026)$ & 0.039 & $(0.040)$ & -0.036 & $(0.035)$ & 0.0040 & $(0.028)$ \\
\hline Constant & & & & & & & & & & \\
\hline $\mathrm{N}$ & 268 & & 268 & & 144 & & 124 & & 241 & \\
\hline
\end{tabular}

Note. Explanatory variables are a dummy for the student sample, socio demographic variables, experimental measures of conditional co-operator and free-rider, and the factors. Rational subjects are those who do respond rationally to the introduction of the sanction. 


\section{Supplementary Online Appendix:}

The following pages are not intended to be published. They will be made available on the homepage of the journal.

The online appendix includes additional tables and graphs (Appendix A), additional analyses (Appendix B) and the experimental protocol

(Appendix C).

\section{Appendix A: Additional Tables and Graphs}

Table A.1:

\begin{tabular}{c|cccc}
\hline \hline \multirow{2}{*}{ Session } & \multicolumn{4}{|c}{ Round } \\
\cline { 2 - 5 } & 2 & 3 & 4 & 5 \\
\hline 1 & Endo & ExoLaw & NoLaw & EndoPay \\
2 & Endo & NoLaw & EndoPay & ExoLaw \\
3 & NoLaw & EndoPay & Endo & ExoLaw \\
4 & ExoLaw & EndoPay & NoLaw & Endo \\
5 & EndoPay & Endo & ExoLaw & NoLaw \\
\hline 6 & Endo & ExoLaw & NoLaw & \\
7 & Endo & NoLaw & ExoLaw & \\
8 & NoLaw & Endo & ExoLaw & \\
9 & ExoLaw & NoLaw & Endo & \\
10 & Endo & ExoLaw & NoLaw & \\
\hline \hline
\end{tabular}

Chronologic treatment plan, by session and round: The first round is omitted as at the beginning of each session we tested for conditional cooperation. We did not conduct EndoPay with workers (sessions 6-10). We arrange different treatments at random as the table shows to avoid round effect.

Table A.2:

\begin{tabular}{c|cccc}
\hline \hline \multirow{2}{*}{ Session } & \multicolumn{4}{|c}{ Round } \\
\cline { 2 - 5 } & NoLaw & ExoLaw & Endo & EndoPay \\
\hline 1 & 4 & 3 & 2 & 5 \\
2 & 3 & 5 & 2 & 4 \\
3 & 2 & 5 & 4 & 3 \\
4 & 4 & 2 & 5 & 3 \\
5 & 5 & 4 & 3 & 2 \\
\hline 6 & 4 & 3 & 2 & \\
7 & 3 & 4 & 2 & \\
8 & 2 & 4 & 3 & \\
9 & 3 & 2 & 4 & \\
10 & 4 & 3 & 2 & \\
\hline \hline
\end{tabular}


Table A.3:

\begin{tabular}{l|cccc}
\hline \hline Session & NoLaw & ExoLaw & Endo & EndoPay \\
\hline students & 2 & 2 & 2 & 2 \\
& 3 & 3 & 2 & 3 \\
& 4 & 4 & 3 & 3 \\
& 4 & 5 & 4 & 4 \\
& 5 & 5 & 5 & 5 \\
\hline \multirow{2}{*}{ orkers } & 2 & 2 & 2 & \\
& 3 & 3 & 2 & \\
& 3 & 3 & 2 & \\
& 4 & 4 & 3 & \\
& 4 & 4 & 4 & \\
\hline \hline
\end{tabular}

List of rounds in which treatments are played, by student/worker: This table helps to detect whether certain treatments were systematically played in later/earlier rounds. 
Table A.4: Responses to attitudinal questions

\begin{tabular}{|c|c|c|c|c|c|c|c|}
\hline & \multicolumn{2}{|c|}{ Mean Value } & \multirow[t]{2}{*}{ T-Value } & \multicolumn{2}{|c|}{ Std. Dev. } & \multicolumn{2}{|c|}{ Number of } \\
\hline & Students & Workers & & Students & Workers & Students & Workers \\
\hline \multicolumn{8}{|l|}{ Working/living atmosphere ${ }^{\mathrm{a}}$} \\
\hline Most people in this university (factory) are basically honest and can be trusted. & 1.93 & 2.14 & $-2.76 * * *$ & 0.47 & 0.68 & 150 & 148 \\
\hline People in this university (factory) are mostly interested in their own well-being. & 2.09 & 1.99 & $1.92 *$ & 0.56 & 0.67 & 150 & 146 \\
\hline In this university (factory) one has to be alert, or someone will take advantage of you. & 2.96 & 2.61 & $4.73 * * *$ & 0.54 & 0.71 & 150 & 147 \\
\hline If you have a problem there is always someone in this university (factory) to help you. & 1.89 & 1.97 & -1.56 & 0.49 & 0.47 & 150 & 148 \\
\hline \multicolumn{8}{|l|}{ Items of the Factors ${ }^{\mathrm{a}}$} \\
\hline People who break the law should be given stiffer sentence. & 2.57 & 2.34 & $2.49 * * *$ & 0.65 & 0.70 & 150 & 146 \\
\hline Schools should teach children to obey authority. & 3.27 & 2.84 & $5.38 * * *$ & 0.55 & 0.70 & 150 & 147 \\
\hline Young people today do not have enough respect for traditional values. & 2.07 & 2.05 & 0.33 & 0.56 & 0.53 & 150 & 148 \\
\hline People don't know the difference between right and wrong anymore. & 2.58 & 2.61 & -0.43 & 0.69 & 0.72 & 149 & 145 \\
\hline Our leaders know what is best for us. & 2.97 & 2.23 & $8.86 * * *$ & 0.67 & 0.65 & 148 & 145 \\
\hline $\begin{array}{l}\text { Obedience and respect for authority are the most important values children should } \\
\text { learn. }\end{array}$ & 3.27 & 2.64 & $6.84 * * *$ & 0.72 & 0.80 & 150 & 147 \\
\hline Getting promotions is about hard work and persistence, not who you know. & 1.86 & 2.12 & $-3.04 * * *$ & 0.66 & 0.72 & 148 & 146 \\
\hline Most people can learn to be leaders- it's not a matter of birth. & 2.06 & 2.03 & 0.63 & 0.68 & 0.72 & 148 & 145 \\
\hline I am very persevering - and I usually accomplish what I set out to do. & 2.04 & 1.95 & 1.57 & 0.56 & 0.56 & 148 & 146 \\
\hline Because no one can predict the future there is little point in making plans. & 3.11 & 2.99 & $1.92 *$ & 0.61 & 0.62 & 148 & 142 \\
\hline Winning is everything. & 2.95 & 2.78 & $2.3 * *$ & 0.67 & 0.71 & 148 & 145 \\
\hline When another person does better than I do, I get tense and aroused. & 2.16 & 2.15 & 0.20 & 0.54 & 0.58 & 148 & 144 \\
\hline Without competition it is not possible to have a good society. & 2.13 & 2.00 & $1.67 *$ & 0.64 & 0.54 & 148 & 145 \\
\hline I feel good when I co-operate with others. & 1.9 & 1.97 & -1.26 & 0.48 & 0.43 & 148 & 143 \\
\hline It is my duty to take care of my family, even when I have to sacrifice what I want. & 1.91 & 1.92 & 0.00 & 0.62 & 0.58 & 148 & 142 \\
\hline I respect the majority's wishes in groups of which I am a member. & 1.91 & 1.92 & -0.25 & 0.42 & 0.38 & 148 & 142 \\
\hline I am more likely to accomplish my goals if I work by myself. & 2.53 & 2.33 & $2.48 * * *$ & 0.68 & 0.63 & 148 & 144 \\
\hline
\end{tabular}

I am more likely to accomplish my goals if I work by myself.

The questions are standard questions that aim at identifying attitudinal stances with reference to psychological patterns such as collectivism, respect for authority or attitudes towards competition and locus of control. The table represents the order the questions were asked in the ex-post questionnaire. Statistically significant differences between workers and students emerge especially regarding the general level of trust (which is higher in the worker sample) and the values towards authority (students are less supportive of norms of obedience). a) 4-point scale: 1 (strongly agree), 2(agree), 3(disagree), 4 (strongly disagree). 
Figure A.1:

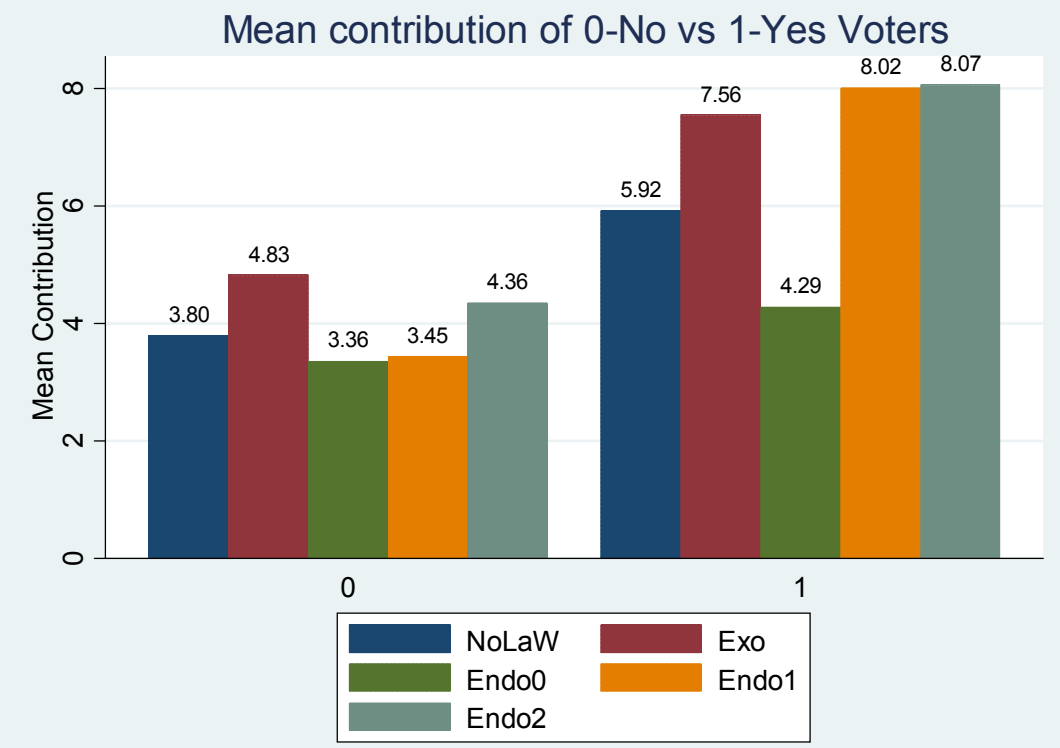

Mean contribution of No- versus Yes-voters depending on information about shares of rule supporters (graphical illustration of Table III in the main text). Contribution levels in the Yes sample are consistently higher than the contribution levels of the No sample. In the No voter and Yes subsample, ExoLaw rule results into higher contribution than ExoNoLaw. Endo generate more contribution than ExoNoLaw and Endo2 also a contribution more than ExoLaw in Yes subsample. The information effects, defined as Endol vs. Endo2 of those voting "yes" and Endo0 vs. Endol of those voting "no", are not significant.

Table A.5:

\begin{tabular}{|c|c|c|}
\hline & Low obey & High obey \\
\hline & \multicolumn{2}{|c|}{ Mean Value } \\
\hline Contrib. & 4.09 & 5.17 \\
\hline \multicolumn{3}{|l|}{ ExoNoLaw } \\
\hline Contrib. Endo & 4.65 & 5.25 \\
\hline Contrib. ExoLaw & 4.77 & 6.93 \\
\hline \multirow[t]{2}{*}{$\mathrm{N}$} & 132 & 167 \\
\hline & \multicolumn{2}{|c|}{ Mean Difference } \\
\hline ExoLaw vs & $0.68^{*}$ & $1.76 * * *$ \\
\hline \multicolumn{3}{|l|}{ ExoNoLaw } \\
\hline Endo vs ExoLaw & -0.12 & $-1.68 * * *$ \\
\hline Endo vs & $0.56^{*}$ & 0.07 \\
\hline ExoNoLaw & & \\
\hline
\end{tabular}


Figure A.2:
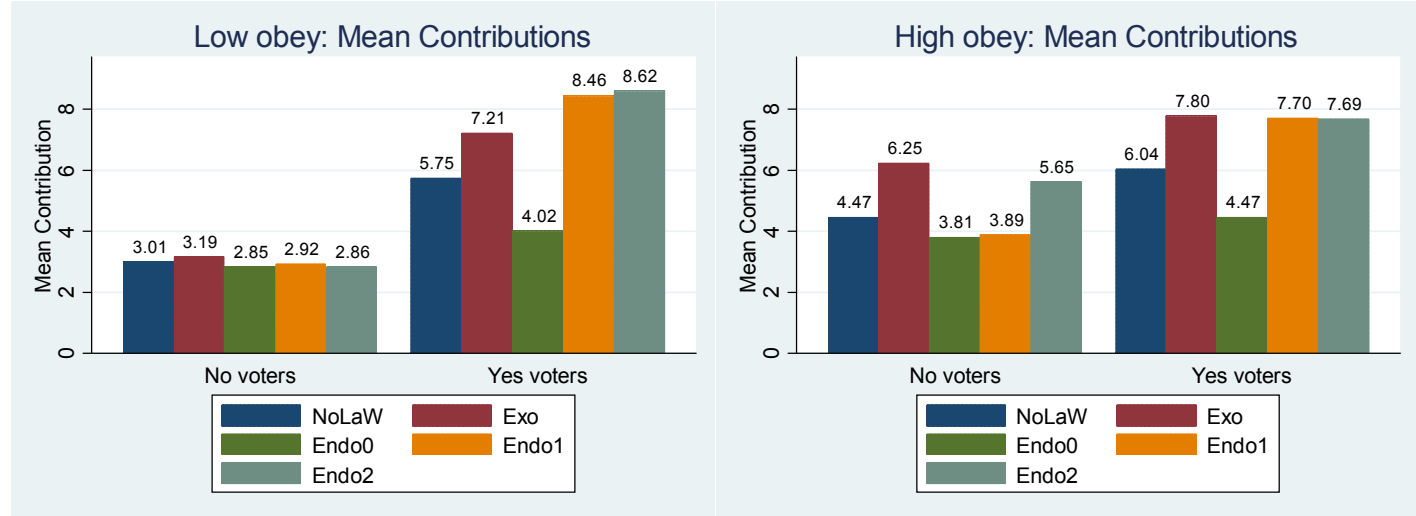

Mean Contribution between treatments by voter type for subsamples of Low obey $(n=132)$ and High obey $(n=167)$.

Figure A.3:
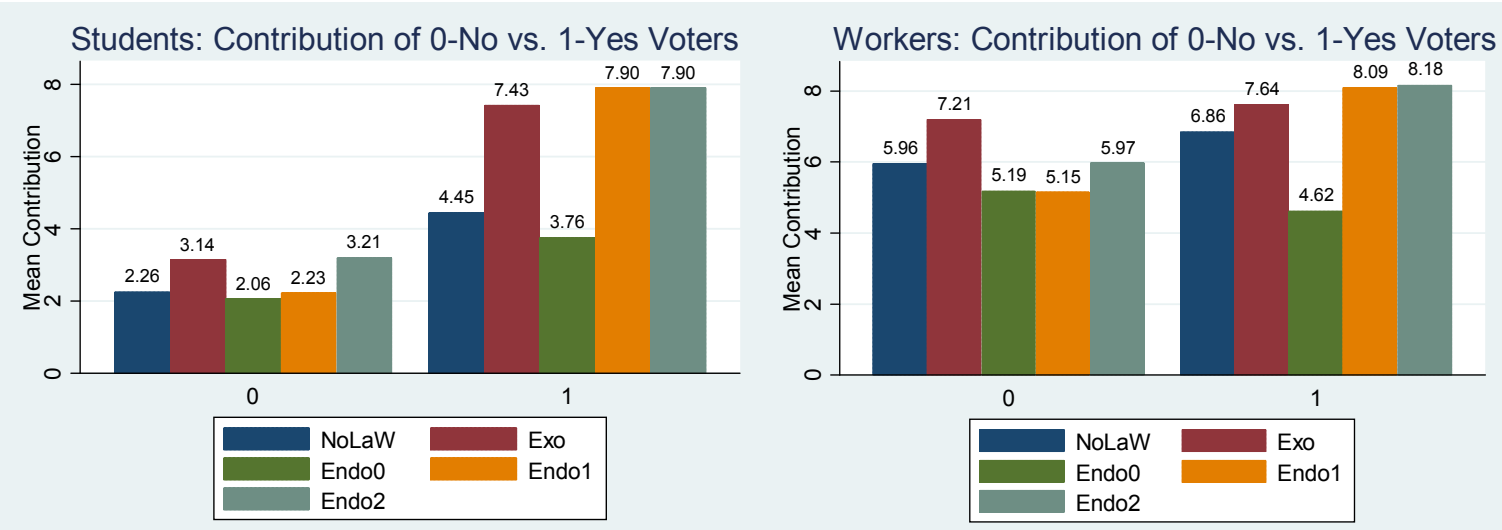

Mean contribution of No- versus Yes-voters depending on regime and information about shares of rule supporters, separately for students (left) and workers (right). A visual inspection of the graphs suggests that there is no information effect (Endo0 = Endo1 for No voters, Endo1 = Endo2 for Yes voters). Again, we find slightly positive democracy effects when the rule is implemented for Yes voters (Endo2 $>$ ExoLaw) and substantial negative democracy effects if the rule is not implemented (Endo $0<\mathrm{NoLaw}$ ). In tendency, the negative democracy effects under no implementation become stronger in the worker subsample and for rule supporters. 
Figure A.4: Distribution of Contributions, by regime and rule supporter share

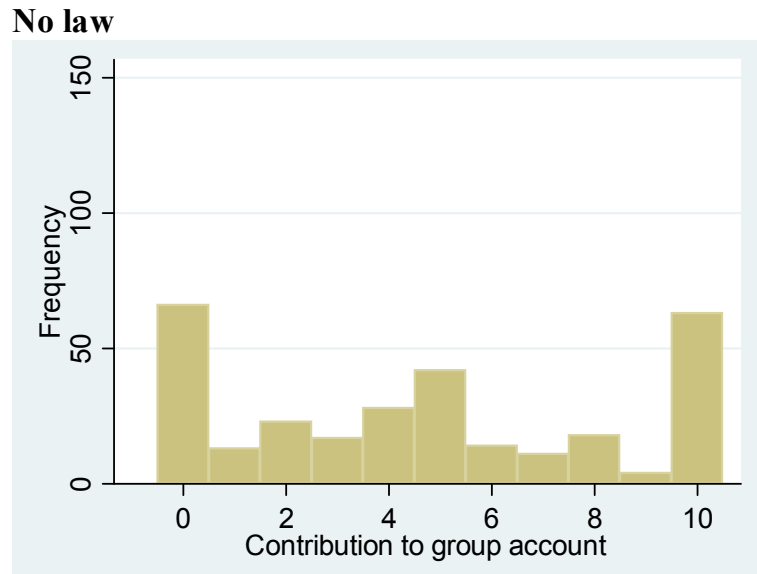

Endo 0

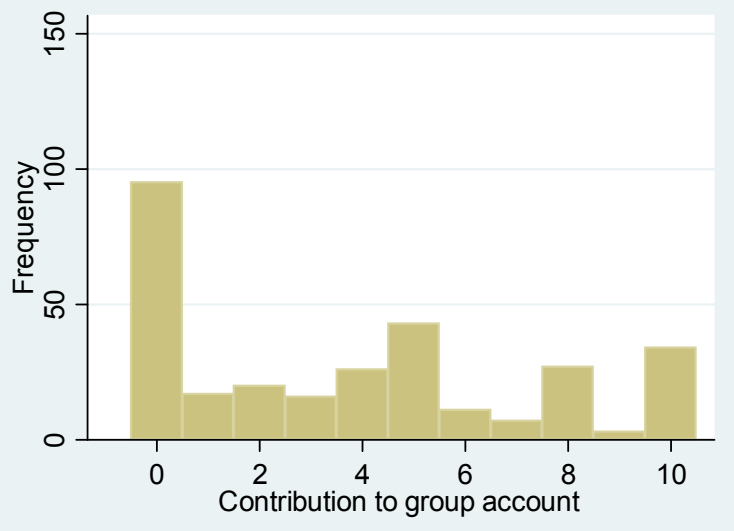

Endo 1

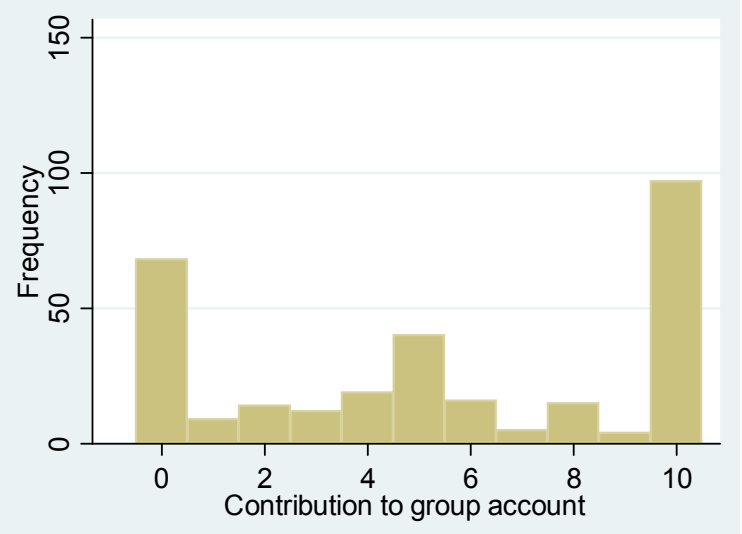

Exo law

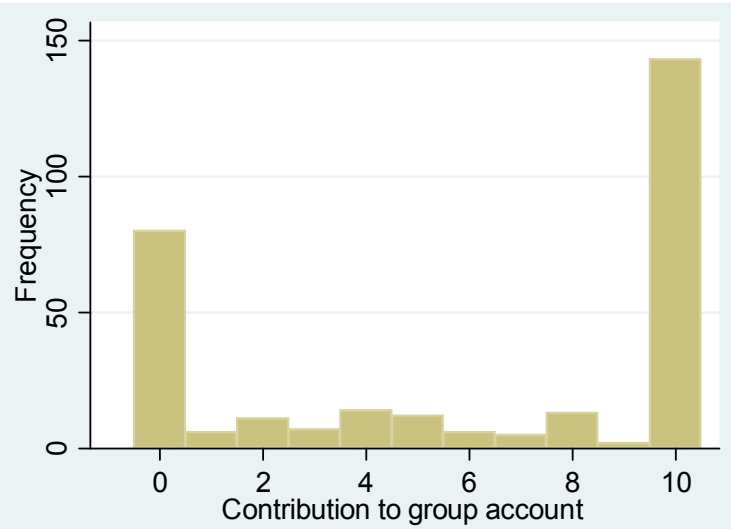

Endo 2

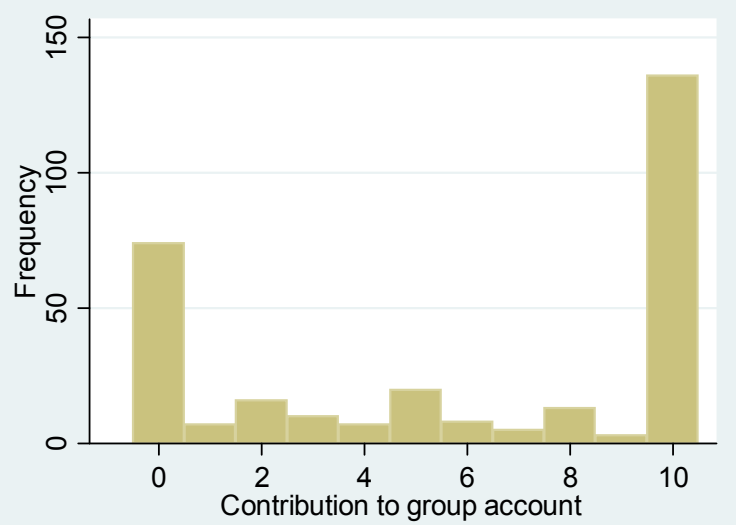

The figures show distribution of contributions depending on regime and information about shares of rule supporters. 


\section{Appendix B: Additional Analyses}

\subsection{Factor analyses}

Factor analysis of the responses to the attitudinal questions allows for clustering a set of six more general attitudinal stances (Table B.1). This negates the influence of idiosyncratic measurement error within each of the construct variables, while maximising the likelihood of measuring the underlying concept more accurately. For each construct, factor scores were calculated, each with a standardised mean of 0 and a standard deviation of 1 , and these were used in the subsequent econometric analysis. We use these factors to explain the observed behavior in the experiments:

1. "Obey authority" reflects the tendency to expect obedience from subordinates, which in the Chinese case refers to the Confucian value of "filial piety" (obedience to parents and elders). In the cited literature on cross-cultural value comparisons, values towards accepting authority are mostly measured by the indicator of 'power distance', based on questions such as whether subordinates should always obey to the superiors, or whether rank should be reflected in privileges. However, these indicators might also capture intolerance, aggression, and conservatism that differ from authoritarianism (Feldman 2003). Recent works have reached the conclusion that child-rearing values are a better indicator of authoritarianism since they avoid reference to specific political situations (Stenner 2005). Especially good measure is the world value survey item "whether one considers it especially important for children to learn obedience"..

2. "Demand for punishment" reveals dissatisfaction with societal states in which deviance is not adequately sanctioned.

3. "Locus of control" gives information about the degree by which an individual perceives herself to be in charge of actions taken and believes that action results are determined by individual efforts.

4. "Collectivism" reflects the tendency to subordinate individual interest to the interest of the group to which the individual assigns herself. 
5. "Competitiveness" manifests the willingness of the individual to compete against others and to perceive individual satisfaction in terms of performance in competitive contexts. 
Table B.1

Results of factor analysis of attitudinal questions

\begin{tabular}{|c|c|c|c|c|c|c|c|}
\hline \multirow[t]{2}{*}{ Factors } & \multirow[t]{2}{*}{ Items } & \multicolumn{6}{|c|}{ Loadings } \\
\hline & & 1 & 2 & 3 & 4 & 5 & 6 \\
\hline \multirow{3}{*}{$\begin{array}{l}\text { Obey authority } \\
(33 \%)^{\mathrm{a}}\end{array}$} & Schools should teach children to obey authority. & 0.828 & & & & & \\
\hline & Our leaders know what is best for us. & 0.604 & & & & & \\
\hline & Obedience and respect for authority are the most important values children should learn. & 0.839 & & & & & \\
\hline \multirow{3}{*}{$\begin{array}{l}\text { Demand for punishment } \\
(25 \%)\end{array}$} & People who break the law should be given stiffer sentence. & & 0.483 & & & & \\
\hline & Young people today do not have enough respect for traditional values. & & 0.660 & & & & \\
\hline & People don't know the difference between right and wrong anymore. & & 0.813 & & & & \\
\hline \multirow{4}{*}{$\begin{array}{l}\text { Locus of control } \\
(40 \%)\end{array}$} & Getting promotions is about hard work and persistence, not who you know. & & & 0.703 & & & \\
\hline & Most people can learn to be leaders- it's not a matter of birth. & & & 0.722 & & & \\
\hline & I am very persevering - and I usually accomplish what I set out to do. & & & 0.687 & & & \\
\hline & Because no one can predict the future there is little point in making plans. & & & 0.339 & & & \\
\hline \multirow{3}{*}{$\begin{array}{l}\text { Collectivism } \\
(23 \%)\end{array}$} & I feel good when I co-operate with others. & & \multirow{3}{*}{\multicolumn{4}{|c|}{$\begin{array}{l}0.701 \\
0.566 \\
0.622\end{array}$}} & \\
\hline & It is my duty to take care of my family, even when I have to sacrifice what I want. & & & & & & \\
\hline & I respect the majority's wishes in groups of which I am a member. & & & & & & \\
\hline \multirow{3}{*}{$\begin{array}{l}\text { Competitiveness } \\
(20 \%)\end{array}$} & Winning is everything. & & & & & 0.580 & \\
\hline & When another person does better than I do, I get tense and aroused. & & & & & 0.627 & \\
\hline & I am more likely to accomplish my goals if I work by myself. & & & & & 0.692 & \\
\hline \multicolumn{8}{|c|}{$\begin{array}{l}\text { Factor analysis of the responses to the attitudinal questions allows for clustering a set of six more general attitudinal stances: Obey authority, Demand for } \\
\text { punishment, Locus of control, Collectivism and Competitiveness. All of the response directions to these questions are adjusted in the data. Original data was recoded } \\
\text { in order to have larger values (4) correlate positively with the factor. Thus, the scale of most variables in APPENDIX } 8 \text { of the Maintext were changed so that } \\
4=\text { strongly agree. Extraction method: The eigenvalues of the factors were all }>1 \text {; The used Kaiser-Meyer-Olkin measure was always }>0.6 \text {, therefore acceptable for } \\
\text { factor analysis. The items of the factors "Obey authority" and "Demand for punishment" were examined together. The items of "Collectivism" and } \\
\text { "Competitiveness" factors were considered together, one item was removed. The locus of control factor includes all four examined items. a) The percentages } \\
\text { represent the proportion of explained variance. }\end{array}$} \\
\hline
\end{tabular}




\subsection{Formal identification of partial effects}

\section{Identification strategy}

Subsequently, we analyse the pooled sample, using the internal differentiation into the two groups as a robustness check. We distinguish between different variants of the game, depending on whether and how the 'Law', i.e. the rule of punishment is implemented. Due to the randomised design, identifying differences between ExoNoLaw, ExoLaw and Endo is simply a matter of mean comparisons. However, since in the Endo treatment some groups have implemented the law while others have not, the democracy premium is not simply obtained by comparing Endo to ExoLaw. Following earlier related contributions (Dal Bo et al. 2010), we also need to consider the information effect that may influence the behavior of the subjects. We thus need to distinguish the rule effect and information effect from the democracy premium. ${ }^{11}$

Our benchmark is the exogenous non-implementation of the rule (ExoNoLaw) with contribution Contr $_{i, \text { NoLaw }}$. If the rule is implemented exogenously (ExoLaw), there might be an additional exogenous rule effect $\alpha_{i, \text { ExoLaw }}$. Under democratic decision making (Endo), rule effects could be more diverse. Besides the actual democratic rule implementation effect, there is always additional information revealed in an election, i.e. the election result. This type of information effect has to be taken into account. For example, an unanimous agreement to implement the rule might motivate group members even more to abide by it. Hence, relative to ExoNoLaw there could be the effect of endogenous non-implementation $\alpha_{i, \text { Demo(NoLaw) }}$, of endogenous implementation $\alpha_{i, \text { Demo(Law) }}$ and an information effect $\alpha_{i, \text { Info\# }}$ depending on the number of other yes-voters \#.

\footnotetext{
${ }^{11}$ According to Dal Bó, Foster and Putterman (2010), only 8\% of the total effect from voting on cooperation was caused by self-selection and only $20 \%$ of the democracy effect was due to the information provided to subjects.
} 
Formally, individual contributions ( Contr $_{i}$ ) depend on rule implementation (Law) and democratic decision making (Endo) as follows:

$$
\begin{aligned}
& \text { Contr }_{i}= \\
& \quad \text { Contr }_{i, \text { ExoNoLaw }}+\alpha_{i, \text { ExoLaw }} \operatorname{Law}+\alpha_{i, \text { Demo(Law })} \operatorname{Law} \cdot \text { Endo }+\alpha_{i, \text { Demo }(\text { NoLaw })}(1-\text { Law }) \cdot \text { Endo }+\alpha_{i, \text { Info \# }}
\end{aligned}
$$

This formalization is not very restrictive, as all effects may vary across individual types. Identifying different partial effects is only possible due to the within-subject variation in institutions and because subjects reveal their reaction to different choices of group members in the strategy method. In particular, we have contributions under democratic implementation and non-implementation for each individual.

The exogenous rule effect $\alpha_{i, \text { ExoLaw }}$ is simply the individual difference between contributions under ExoNoLaw and ExoLaw. The effect of endogenous non-implementation $\alpha_{i, \text { Demo(NoLaw) }}$ (Democracy Effect No Law) is the individual difference between ExoNoLaw and contributions with democratic non-implementation (Endo0/Endo1), minus the information effect. The effect of endogenous implementation $\alpha_{i, \text { Demo(Law) }}$ (Democracy Effect Law) is similarly given by the difference between ExoLaw and contributions with democratic implementation (Endo1/Endo2), minus the information effect.

We propose the following strategy to test for the information effect: If an individual votes for rule implementation, then the law is enacted when there is at least one other supporter in the group of three (Endo1/Endo2). Conversely, opponents of the rule can avoid the law if there is at most one supporter of the rule in the group (Endo0/Endo1). This setting provides variation in information (number of group members in favor of the rule) while keeping the rule and the voter type constant. We can therefore identify $\alpha_{i, \text { Info } 2}-\alpha_{i, \text { Info } 1}$ for rule supporters and $\alpha_{i, \text { Info } 1}-\alpha_{i, \text { Info } 0} f o r$ rule opponents. Note that $\alpha_{i, I n f o 0}$ is not identified separately from the democracy effect. We 
therefore restrict it to zero, implying that its effect is included in the democratic rule (non)implementation effect.

Subsequently, we try to disentangle different effects that work behind the generation of the results. Following earlier related contributions, we need to consider different factors that may influence the behavior of the subjects.

Let us consider the contributions for individual $i$ under any scheme, resulting from the combination of the following effects:

1. Contr $_{i, \text { NoLaw }}$ is the baseline contribution under no law and no democracy;

2. $\alpha_{i, \text { ExoLaw }}$ is the effect of an exogenous rule;

3. $\alpha_{i, \text { Demo(Law) }}$ is the additional rule effect if it is chosen democratically

4. $\alpha_{i, \text { Demo(NoLaw) }}$ is the effect on top of Contr $_{i, \text { NoLaw }}$ if no rule is democratically chosen

5. $\alpha_{i, \text { Info\# }}$ is the information effect of observing \# co-players voting for a rule (relative to some expected number)

So, we have:

Contr $_{i}=$

Contr $_{i, \text { NoLaw }}+\alpha_{i, \text { ExoLaw }} \operatorname{Law}+\alpha_{i, \text { Demo }(\text { Law })} L a w \cdot$ Endo $+\alpha_{i, \text { Demo }(\text { NoLaw })}(1-$ Law $) \cdot$ Endo $+\alpha_{i, \text { Info\# }}$

Information Effect $\left(\alpha_{i, \text { Infö\#}}\right)$

We can identify $\alpha_{i, \operatorname{lnf} o 2}-\alpha_{i, \ln f \circ 1}$ for Yes voters and $\alpha_{i, \ln f \circ 1}-\alpha_{i, \operatorname{lnf} f 0}$ for No voters, as indicated in the main text. In both cases the information on co-player types varies without changing other circumstances:

$$
\begin{array}{ll}
\alpha_{i, \operatorname{lnfo} 2}-\alpha_{i, \operatorname{lnfo1} 1}=\text { Contr }_{i, \text { Endo } 2}-\text { Contr }_{i, \text { Endo } 1} & \text { for Yes voters } \\
\alpha_{i, \text { Info1 }}-\alpha_{i, \operatorname{lnfo0} 0}=\text { Contr }_{i, \text { Endo1 }}-\text { Contr }_{i, \text { Endo } 0} & \text { for No voters }
\end{array}
$$

In both cases the effect is very small and statistically indistinguishable from zero (shown in Table 1 in the main text / Figure A.1). If there was an information effect, this should mean a 
change in $\alpha_{i, \text { Info\# }}$ depending on Info\#. Therefore we feel confident to assume $\alpha_{i, \text { Info\# }}=0$ and hence:

$$
\begin{aligned}
& \text { Contr }_{i}= \\
& \quad \text { Contr }_{i, \text { NoLaw }}+\alpha_{i, \text { ExoLaw }} L a w+\alpha_{i, \text { Demo(Law })} L a w \cdot \text { Endo }+\alpha_{i, \text { Demo }(\text { NoLaw })}(1-\text { Law }) \cdot \text { Endo }
\end{aligned}
$$

\section{Exogenous Rule Effect $\left(\alpha_{i, \text { ExoLaw }}\right)$}

Here we simply compare contributions under ExoLaw vs. ExoNoLaw, because

$$
\alpha_{i, \text { ExoLaw }}=\text { Contr }_{i, \text { ExoLaw }}-\text { Contr }_{i, \text { ExoNoLaw }}
$$

The estimated effect is $1.29 * * *$ (see Table VI).

\section{Democracy Effect $\left(\alpha_{i, \text { Demo(Law) }}, \alpha_{i, \text { Demo(NoLaw })}\right)$}

For the democracy effect, let us use special cases of equation $(1 *)$ :

$$
\begin{gathered}
\text { Contr }_{i, \text { Endo } 2}=\text { Contr }_{i, \text { ExoNoLaw }}+\alpha_{i, \text { ExoLaw }}+\alpha_{i, \text { Demo(Law })} \text { and } \text { Contr }_{i, \text { ExoLaw }}=\text { Contr }_{i, \text { ExoNoLaw }}+\alpha_{i, \text { ExoLaw }} \\
\text { Hence } \\
\alpha_{i, \text { Demo(Law })}=\text { Contr }_{i, \text { Endo } 2}-\text { Contr }_{i, \text { ExoLaw }} \\
\text { Similarly } \quad \alpha_{i, \text { Demo(NoLaw })}=\text { Contr }_{i, \text { Endo } 0}-\text { Contr }_{i, \text { ExoNoLaw }}
\end{gathered}
$$


In the data this on average looks as follows (computed from Table III in the main text):

Table B.2 Democracy effect

\begin{tabular}{cccc}
\hline \hline $\begin{array}{c}\text { Yes voters? } \\
\text { Democracy effect } \backslash\end{array}$ & $\begin{array}{c}1 \\
(\mathrm{~N}=173)\end{array}$ & $\begin{array}{c}\text { ALL } \\
(\mathrm{N}=126)\end{array}$ & $(\mathrm{N}=300)$ \\
\hline$\hat{E}\left[\alpha_{i, \text { Demo (NoLaw) }}\right]$ & -0.43 & -1.63 & -0.94 \\
$\hat{E}\left[\alpha_{i, \text { Demo(Law) }}\right]$ & -0.47 & 0.52 & -0.06
\end{tabular}

Weighting the two democracy effects with the proportion of groups where the rule is implemented (37 out of 100), we obtain an overall democracy effect of $-0.61^{* * *}$. The variance of the overall democracy effect is calculated along the following lines ${ }^{12}$ :

$$
\begin{aligned}
& \operatorname{Var}\left(w_{0} \bullet \hat{\alpha}_{0}+w_{1} \bullet \hat{\alpha}_{1}\right) \\
& =w_{0}{ }^{2} \cdot \operatorname{Var}\left(\hat{\alpha}_{0}\right)+w_{1}{ }^{2} \bullet \operatorname{Var}\left(\hat{\alpha}_{1}\right)+2 \cdot w_{0} \bullet w_{1} \bullet \operatorname{Cov}\left(\hat{\alpha}_{0}, \hat{\alpha}_{1}\right)
\end{aligned}
$$

A common problem in the literature is that groups implementing the law are compared with nonimplementing groups. This comparison obviously suffers from a selection problem, because groups enacting the law consist of a higher share of Yes voters. We avoid selection effects by having each participant making choices under all possible treatments: Groups enacting the rule consist of different types and more cooperative people are more likely to end up with the law enacted (selection effect). Simply comparing contributions with and without the rule in the endogenous setting would yield a biased estimate, because more Yes voters are in groups endogenously enacting the rule. Doing this 'wrong' across-subject design shows that contributions are 3.88 points higher where the rule is implemented. Note that there are more workers that support the rule than students and workers have higher contribution levels. However, the tendency of rule supporters to contribute more holds in both the student and the worker subsample. This means that there would be a selection effect in the endogenous schemes. Groups that enact a rule probably consist of more cooperative types. Accordingly, for rule supporting individuals Endo does much better than ExoNoLaw and not significantly worse than

\footnotetext{
${ }^{12}$ Estimating the respective variances and covariances by their sample analogues results in a standard deviation of the overall effect of 0.15 . The exact calculation algorithm is available upon request.
} 
Exo while in the opponents subsample Endo does no better than ExoNoLaw and much worse than Exo.

\subsection{Robustness check: Subsample analysis of workers and students}

The separate analysis of the student and worker samples serves as a robustness check. For example, the already high average cooperation within the worker sample might make it more difficult to find a positive democracy premium. However, this reservation should not hold in the student sample with much lower average cooperation levels. Thus, by analyzing each sample isolated, we can test whether our findings are robust to the strong level effects in cooperation. We do not intend to compare these vastly different samples ${ }^{13}$, but we test whether we find similar relative effects in both samples. We argue that a supposedly Chinese value system will show up especially clearly if the same democracy effects appear in both the student and the worker sample, even if the two groups manifest level effects that might reflect the impact of education or generational differences.

\section{TABLE VII}

Mean contribution of student vs. workers, three regimes

\begin{tabular}{llllc}
\hline \hline & \multicolumn{3}{c}{ Mean Value } & \multirow{2}{*}{$\begin{array}{c}\text { Mean difference between } \\
\text { Students and Workers }\end{array}$} \\
\cline { 2 - 4 } & All & Students & Workers & $-0.19^{* * *}$ \\
Voted Law & & 0.33 & 0.52 & $-3.45^{* * *}$ \\
Contrib. ExoNoLaw & 4.69 & 2.97 & 6.42 & $-2.63 * * *$ \\
Contrib. Endo & 4.98 & 3.67 & 6.30 & $-2.89 * * *$ \\
Contrib. ExoLaw & 5.98 & 4.54 & 7.43 & $-2.29 * * *$ \\
Contrib. Endo0 & 3.75 & 2.61 & 4.90 & $-2.59 * * *$ \\
Contrib. Endo1 & 5.37 & 4.08 & 6.67 & $-2.37 * * *$ \\
Contrib. Endo2 & 5.92 & 4.74 & 7.11 & \\
$\quad$ N & 299 & 150 & 149 &
\end{tabular}

${ }^{13}$ The "two societies" (Whyte 2010) of China's countryside and its megacities also feature many institutional differences, such as in the social security system: Whereas the urban population is at least partly covered by public social support systems, the rural population, until recently, had to rely on traditional forms of social support in the family and community. Thus, the difference between our samples is not rooted in a special corporate culture of Fuxing Company, but in divergent social and cultural conditions in China's urban and rural societies. 


$\begin{array}{llll}\text { Mean Difference } & & & \\ \text { ExoLaw vs ExoNoLaw } & 1.29 * * * & 1.56 * * * & 1.01 * * * \\ \text { Endo vs ExoLaw } & -1.00^{* * *} & -0.87 * * * & -1.13 * * * \\ \text { Endo vs ExoNoLaw } & 0.29 & 0.70^{* * *} & -0.12 \\ \text { Endo0 vs ExoLaw } & -2.23 * * * & -1.93 * * * & -2.53 * * * \\ \text { Endo1 vs ExoLaw } & -0.61 * * * & -0.46 & -0.76 * * \\ \text { Endo2 vs ExoLaw } & -0.06 & 0.20 & -0.32\end{array}$

Note. The results highlight two insights. First, contribution levels in the worker sample are consistently higher than the contribution levels of the student sample. Second, in both samples the contribution levels in the ExoLaw regime are the highest, and there is no substantial "democracy effect" of the Endo regime (see discussion in the main text). However, students also show a positive effect of the Endo regime relative to the ExoNoLaw regime.

\subsection{Comparing our results to the literature}

Local level studies suggest that democratic procedures make citizens respond more cooperative to the implemented policies; especially that policies or laws directed towards cooperation stimulate more cooperation when the policies or the laws have been elected in a democratic process. For example, this has been prominently stated by Ostrom (1990) in her design principles for successful local common pool resource management. When individuals affected by a resource regime participate in decision-making and modifying their rules those rules are more likely to be perceived as fair and tailored to the local circumstances. Bardhan (2000) found by analysing forty-eight irrigation systems in India that the quality of maintenance was lower for those where farmers perceived a local elite to have made the rules. Those farmers who responded that the rules have been crafted by most farmers had a positive attitude towards water allocation and higher rule compliance. Sekher (2000) found similar results for forest management in India and Yoder (1994) and Lam (1998) for farmer-designed-and-governed irrigation systems in Nepal. Also Swiss cantons that have higher democratic participation have lower tax evasion (Pommerehne and Weck-Hannemann 1996). Most studies on the relationship of participation at 
the workplace and productivity show also positive results (Zwick 2004) except Godard and Delaney (2000) and Cappelli and Neumark (2001). As argued throughout the main text, our results are in sharp contrast to a large number of experiments from western democratic countries using different experimental designs (18-20). Not all setups are directly comparable, but we try to provide the essence of the most prominent studies in this section. Comparability is not a problem with the Tyran and Feld (2006). Because of our choice to implement the public good game as in (Tyran and Feld 2006), their numbers can be easily compared to our own. They find contribution rates of $30 \%$ under no law (NoLaw), 38\% under exogenous mild law (ExoLaw) and 47\% under endogenous rule choice $(E n d o)^{14}$. This means that even if not all groups implement the rule, it still performs better than when a rule is set exogenously for everybody. In contrast to us, they cannot infer the voter type in the exogenous institutional settings, though. Sutter, Haigner and Kocher (2010) plays a public good game with rewards and peer punishment as two alternative rule options that can be added to a standard voluntary contribution mechanism either exogenously or by vote. They find a premium of about $8.5 \%$ when the institution is determined endogenously (effect of +1.7 when maximum contribution is 20 , compare column 3 of table 4 ).

Dal Bó, Foster and Putterman (2010) is the paper we most closely relate to regarding the identification strategy for the democracy effect. They play prisoners' dilemma games with a possible fine as a rule that makes cooperation an additional equilibrium. Their outcome is the rate at which players play the cooperative strategy. In the Table III below we report contribution rates of Yes and Novoters under ExoNoLaw, ExoLaw, Endo0 and Endo2. These figures are the basis to calculate the democracy effects. Additionally we calculate democracy effects under no law (DENL) and law (DEL) for Yes and No voters. All those numbers are available for the Dal Bó et

\footnotetext{
${ }^{14}$ Figures on mild exogenous law and no law are taken from Tyran and Feld (2006) (page147). Note that the contribution under Endo is calculated as the weighted average of the $60 \%$ endogenously implementing a mild rule (contribution rate $64 \%$ ) and the $40 \%$ not implementing it (contribution rate $22 \%$ ). Those numbers are given on page 149.
} 
al.'s paper (Dal Bo et al. 2010), which makes it an interesting benchmark. We show our results separately for the worker and student sample, as the latter is probably more comparable to the student sample used in Dal Bó, Foster and Putterman (2010). Most importantly, Dal Bó, Foster and Putterman (2010) find a large positive democracy effect under law implementation for Yes voters. We find no such positive effect in neither of our subsamples. To the contrary, we even find substantial negative democracy effects especially in the worker sample.

Table B.3: Comparison of democracy effects under no law (DENL) and law (DEL) for Yes and No voters between China's sample and Dal Bó et al.'s.

\begin{tabular}{|c|c|c|c|}
\hline & $\begin{array}{l}\text { China: } \\
\text { Workers }\end{array}$ & $\begin{array}{l}\text { China: } \\
\text { Students }\end{array}$ & $\begin{array}{l}\text { Dal Bó, Foster and } \\
\text { Putterman (2010) }\end{array}$ \\
\hline game & \multirow{2}{*}{\multicolumn{2}{|c|}{$\begin{array}{l}\text { Public good game } \\
\text { Contribution rates }\end{array}$}} & Prisoners' dilemma \\
\hline outcome & & & Rates of cooperation \\
\hline no: ExoNoLaw & $60 \%$ & $23 \%$ & $4 \%$ \\
\hline no: ExoLaw & $72 \%$ & $31 \%$ & $42 \%$ \\
\hline no: Endo0 (no rule) & $52 \%$ & $21 \%$ & $15 \%$ \\
\hline no: Endo2 (rule) & $60 \%$ & $32 \%$ & $41 \%$ \\
\hline yes: ExoNoLaw & $69 \%$ & $45 \%$ & $24 \%$ \\
\hline yes: ExoLaw & $76 \%$ & $74 \%$ & $58 \%$ \\
\hline yes: Endo0 (no rule) & $46 \%$ & $38 \%$ & $24 \%$ \\
\hline yes: Endo2 (rule) & $82 \%$ & $79 \%$ & $82 \%$ \\
\hline no: DENL & $\begin{array}{r}-\mathbf{8 \%} \% * * \\
(0.04)\end{array}$ & $\begin{array}{l}-2 \% \\
(0.26)\end{array}$ & $\begin{array}{l}11 \% \\
(0.28)\end{array}$ \\
\hline no: DEL & $\begin{array}{c}-12 \% * * \\
(0.02)\end{array}$ & $\begin{array}{l}1 \% \\
(0.86)\end{array}$ & $\begin{array}{l}-1 \% \\
(0.95)\end{array}$ \\
\hline yes: DENL & $\begin{array}{c}-\mathbf{2 2 \%} \% * * * \\
(0.00)\end{array}$ & $\begin{array}{l}-7 \% \\
(16)\end{array}$ & $\begin{array}{c}0 \% \\
(0.97)\end{array}$ \\
\hline yes: DEL & $\begin{array}{c}5 \% \\
(0.19)\end{array}$ & $\begin{array}{c}5 \% \\
(0.18)\end{array}$ & $\begin{array}{c}24 \% * * * * \\
(0.01)\end{array}$ \\
\hline
\end{tabular}

Note. Contribution rates from the China sample are equivalent to the rates displayed in Appendix 5. The prefix "yes" / "no" indicates the subsamples of Yes and No voters. The democracy effects under no law (DENL) are calculated by Endo0 - ExoNoLaw, democracy effects under law (DEL) by Endo2 - ExoLaw, p-values of differences are in brackets. Figures from (Dal Bo et al. 2010) are copied from table 5, column 2 (p. 2215). In their paper ExoNoLaw = ExoNot, ExoLaw $=$ ExoMod, Endo0 $=$ EndoNot, Endo2 $=$ EndoMod . 


\subsection{The Endogenous Pay Treatment (students only)}

The treatment EndoPay ("pay for voting") has not been tested by Tyran and Feld (2006). This treatment elicits behavior of subjects with a stronger preference for ExoNoLaw or Law. In case at least two subjects decided to pay the Endo treatment was implemented. In case less than two participants from the group of three were willing to pay 2 Yuan from their show-up fee (similar to 2 tokens) we randomly decided whether ExoNoLaw or ExoLaw was played (hence there was no prior default). Participants had to vote and contribute (Endo0, Endo1, Endo2, ExoLaw, ExoNoLaw) without knowing whether more than two participants had paid for the referenda. Our hypothesis was that especially those subjects who decided to pay and voted "yes" have the strongest positive democracy effect. In total $31 \%$ of students were willing to pay in order to vote. Already this figure shows a high acceptance of the idea of voting among Chinese students. In Sutter, Haigner and Kocher (2010) the share of students participating in costly voting was $44 \%$ given lower costs (5\% of endowment compared with $20 \%$ in our case). This might indicate our interpretation of students (especially the older ones) being in favour of democratic principles. The great majority, however, decided not to pay and voted against the law $(69 \%)$.

The reason for deducting the money from the show-up fee instead of the endowment was to have comparable contribution decisions between treatments. Thus, irrespective of their decision to pay for voting, both in NoEndPay and MildEndPay participants had ten tokens endowment. Due to the higher complexity of this treatment we did not carry it out with the sample of workers. By using the strategy method in the endogenously chosen treatments we can further distinguish contributions conditional on the law being in place or not. Thus, we have all required decisions within one session in order to identify the democracy effect (including everybody's contribution decisions when enough group members decide to pay for voting). 
Table B.4: Student sample with the distinction between normal treatment and payment for the right to vote

\begin{tabular}{lccc}
\hline \hline & \multicolumn{2}{c}{ Mean Value } & \multicolumn{2}{c}{ Mean difference between } \\
& $\begin{array}{c}\text { Normal } \\
\text { (Students) }\end{array}$ & $\begin{array}{c}\text { EndoPay } \\
\text { (Students) }\end{array}$ & Normal and EndoPay \\
\hline Pay for vote & -- & 0.31 & -- \\
Voted Law & 0.33 & 0.31 & 0.02 \\
Contrib. & 2.97 & 2.83 & 0.14 \\
ExoNoLaw & 3.67 & 3.38 & 0.29 \\
Contrib. Endo & 4.54 & 4.66 & -0.12 \\
Contrib. ExoLaw & 2.61 & 2.64 & -0.03 \\
Contrib. Endo0 & 4.08 & 3.63 & $0.45^{*}$ \\
Contrib. Endo1 & 4.74 & 4.96 & -0.22 \\
Contrib. Endo2 & 150 & 150 & \\
\multicolumn{1}{c}{$\mathrm{N}$} & Mean Difference & \\
\hline ExoLaw vs & $1.57 * * *$ & $1.83 * * *$ & \\
ExoNoLaw & $-0.87 * * *$ & $-1.28 * * *$ & \\
Endo vs ExoLaw & \multicolumn{2}{c}{ End } & \\
Endo vs & $0.70 * * *$ & $0.55 * *$ & \\
ExoNoLaw & & \\
Endo0 vs ExoLaw & $-1.93 * * *$ & $-2.02 * * *$ & \\
Endo1 vs ExoLaw & -0.46 & $-1.02 * * *$ & \\
Endo2 vs ExoLaw & 0.20 & 0.30 & \\
\hline \hline
\end{tabular}

Average contributions are very similar in EndoPay as compared to Normal. Only contributions of Endo1 are slightly higher in Normal $(p<0.10)$. Also the differences between contributions under different decision types and their significance are very similar. Only in the comparison Endo1 vs ExoLaw the one in EndoPay is significant and the other in Normal not. In sum, effects found in the main analysis can be confirmed in the additional treatment. We do not find stronger democracy effects if people have to pay for voting. 
Table B.5: Student sample comparison between No or Yes to rule subsamples under the distinction between normal treatment and payment for the right to vote

\begin{tabular}{|c|c|c|c|c|c|c|}
\hline & \multicolumn{3}{|c|}{ Students in Normal } & \multicolumn{3}{|c|}{ Students in EndoPay } \\
\hline & \multicolumn{2}{|c|}{ Mean Value } & \multirow{2}{*}{$\begin{array}{c}\text { Mean } \\
\text { difference } \\
\text { between } \\
\text { No and } \\
\text { Yes to rule }\end{array}$} & \multicolumn{2}{|c|}{ Mean Value } & \multirow{2}{*}{$\begin{array}{c}\text { Mean } \\
\text { difference } \\
\text { between No } \\
\text { and Yes to } \\
\text { rule }\end{array}$} \\
\hline & $\begin{array}{l}\text { No to } \\
\text { rule }\end{array}$ & $\begin{array}{l}\text { Yes to } \\
\text { rule }\end{array}$ & & $\begin{array}{l}\text { No to } \\
\text { rule }\end{array}$ & $\begin{array}{l}\text { Yes to } \\
\text { rule }\end{array}$ & \\
\hline Contrib. ExoNoLaw & 2.26 & 4.45 & $-2.19 * * *$ & 2.25 & 4.15 & $-1.9 * * *$ \\
\hline Contrib. Endo & 2.35 & 6.41 & $-4.06 * * *$ & 2.17 & 6.11 & $-3.94 * * *$ \\
\hline Contrib. ExoLaw & 3.14 & 7.43 & $-4.29 * * *$ & 3.77 & 6.65 & $-2.88 * * *$ \\
\hline Contrib. Endo0 & 2.06 & 3.76 & $-1.70 * *$ & 2.20 & 3.63 & $-1.43 * *$ \\
\hline Contrib. Endo1 & 2.23 & 7.90 & $-5.67 * * *$ & 2.15 & 6.98 & $-4.83 * * *$ \\
\hline Contrib. Endo2 & 3.21 & 7.90 & $-4.69 * * *$ & 3.90 & 7.34 & $-3.44 * * *$ \\
\hline $\mathrm{N}$ & 101 & 49 & & 104 & 46 & \\
\hline \multicolumn{7}{|l|}{ Mean Difference } \\
\hline ExoLaw vs ExoNoLaw & $0.88^{* *}$ & $2.98 * * *$ & & $1.53^{* * *}$ & $2.50 * * *$ & \\
\hline Endo vs ExoLaw & $-0.79^{* *}$ & -1.02 & & $-1.07 * * *$ & -0.80 & \\
\hline Endo vs ExoNoLaw & 0.09 & $1.95^{* * *}$ & & -0.08 & $1.96^{* * *}$ & \\
\hline Endo0 vs Endo1 & -0.17 & $-4.14 * * *$ & & 0.05 & $-3.35 * * *$ & \\
\hline Endo1 vs Endo2 & $-.98 * *$ & 0.00 & & $-1.75 * * *$ & -0.37 & \\
\hline $\begin{array}{l}\text { Endo0 vs } \\
\text { ExoNoLaw(DENL) }\end{array}$ & -0.20 & -0.69 & & -0.05 & -0.52 & \\
\hline Endo2 vs ExoLaw (DEL) & 0.07 & 0.47 & & 0.12 & $0.70^{*}$ & \\
\hline
\end{tabular}

The students voting Yes significantly increase the contribution in all of the treatments for both of Normal and Endopay. The contribution changes of Yes/No-voters for different comparison are almost consistent. Compared with ExoLaw, Endo decrease the cooperation for No-voters in both of Normal and Endopay. Endo1 results in higher contribution than Endo0 for Yes-voters but Endo2 higher than Endo1 for No-voters. Again, there is no sign for an information effect (Endo1=Endo2 for yes voters, Endo0=Endo1 for no voters).

\subsection{Determinants of rule choice}

In the prior analysis we have seen that Yes and No voters contribute quite differently under the same circumstances. In particular, individuals in favour of the rule seem to be more cooperative and contribute more, whether a rule is present or not. Correlating the voter type to other individual characteristics might give a better understanding of important differences between types. We hypothesise that determinants of rule choice are whether the person was identified to be a conditional co-operators or free-rider and factors for collectivism, individualism, locus of control, obey authority, demand for punishment and some sociodemographic variables. We displayed the distribution of these variables and their factor loadings 
are displayed in tables S1-3. We further include a trend variable for each round to capture possible learning effects. The estimated Probit models for rule choice are shown in Table B.6.

We would expect that conditional co-operators would vote for the law in the endogenous treatment. Tyran and Feld (2006) analysed expectations of players and found that subjects expect higher compliance with mild law if many others express support for the law and that subjects tend to comply with the law if they expect many others to do so. Closely related to the concept of beliefs and expectation is the notion of conditional cooperation. While in the former the subjects have some uncertainty about the level of others contribution in the latter subjects are told the level of others contribution. Following Tyran and Feld (2006) we would thus expect that conditional cooperators are more likely to vote for the law as they will perceive the signal of others as valuable information about their likely contribution. Interestingly, we only find this relation for the student sample. Of the conditional co-operators in the student sample, 43 percent voted for the law and 23 percent of those who are not conditional co-operators voted for the law $\left(\mathrm{n}=150 ; \chi^{2}=4.8 ; \mathrm{p}<0.05\right)$. In the worker sample it is the other way round. Of the conditional cooperators in the worker sample 46 percent voted for the law and 57 percent of those who are not conditional co-operators voted for the law. In the student sample we only find a very weak effect of conditional co-operators on voting for the introduction of the law (sig. at $10 \%$ level) and selfish players are less likely to vote for the law (sig. at 5\% level). In columns three and four we also find that conditional co-operators are more likely to pay money for the possibility of voting (sig. at $10 \%$ level). However, in the worker sample we surprisingly obtain a negative effect for conditional co-operators. Instead of using the possibility of signalling one's intention to the other workers, the workers who were conditional co-operator prefer not to have the law introduced. We conjecture that the already high contribution of the workers (average 6.2 in round 1) and the high social capital among them did make the law not necessary for the conditional co-operators; 
further, matching with the argument on information effects previously, workers might think that the introduction of the law would express mistrust into others, which contradicts their common knowledge in the shared workplace setting. Of those who voted not to have the law $29 \%$ contributed 8 and more points (17\% contributed fully) when they knew the law was not enacted (i.e. they voted "no" and make their contribution knowing that only one other person voted for the law). Thus, the conditional co-operators do not necessarily change their behavior due to the possibility of voting but they also don't see the need for the law. Our results on conditional cooperator are rather weak and overall it seems that Chinese do not consider the voting information to be important, similarly we did not find an information effect on contributions. Also if we repeat the analysis for conditional cooperators only, we do not find an information effect (table available upon request). Hence there might be no reason to send the voting signal.

Interestingly, we see that workers who articulated to have a high demand for punishment are more likely to vote for the law. Thus, personal opinions that workers have about the society greatly influence their decisions in the experiment. In the pooled sample the effect of the selfish types remains strong and negative and in addition we discover that risk taking in real life becomes positively related to voting for the law (as well as for paying to vote). This might have two reasons: First, people might be unsure about the "value of voting" and thus perceive its use as risky. For example it is also often found that more risk-loving people in developing countries are the first to take-up micro insurance because insurance is perceived as a new and risky product (Giné et al. 2008). Secondly, people might act strategically and vote for the law to increase other players' contribution and at the same time do not comply to the law themselves; again, this matches with the incentive system analysis of the information effects, as the introduction of the law would be a signal that the majority of people are opportunists. This strategy could be profit 
maximizing but it seems rather unlikely given that contributions in endogenously chosen law are not much higher than without law. Also the correlation between risk taking and being a selfish type is zero in our sample and we find that in the case when a very risk-loving player (scale 7-9) votes "yes" and knows that one other player also voted for the law only four players contribute nothing, eight players less than ten, but the large majority of twenty two player contribute fully. Thus, we rather think that voting for the law was perceived as risky by some people in our sample.

Table B.6: Probit regression of rule choice on possible determinants

\begin{tabular}{|c|c|c|c|c|c|c|c|c|}
\hline & \multicolumn{2}{|c|}{$\begin{array}{c}\text { voted Yes } \\
\text { Student sample }\end{array}$} & \multicolumn{2}{|c|}{$\begin{array}{l}\text { paid for voting } \\
\text { Student sample }\end{array}$} & \multicolumn{2}{|c|}{$\begin{array}{c}\text { voted Yes } \\
\text { Worker sample }\end{array}$} & \multicolumn{2}{|c|}{$\begin{array}{c}\text { voted Yes } \\
\text { Pooled sample }\end{array}$} \\
\hline & $(1)$ & (2) & (3) & (4) & $(5)$ & (6) & $(7)$ & (8) \\
\hline conditional cooperator & $\begin{array}{l}0.16^{*} \\
(0.08)\end{array}$ & $\begin{array}{l}0.16^{*} \\
(0.09)\end{array}$ & $\begin{array}{c}0.12 \\
(0.08)\end{array}$ & $\begin{array}{l}0.17 * \\
(0.09)\end{array}$ & $\begin{array}{l}-0.14 * \\
(0.08)\end{array}$ & $\begin{array}{r}-0.27 * * * \\
(0.11)\end{array}$ & $\begin{array}{l}0.0004 \\
(0.06)\end{array}$ & $\begin{array}{l}-0.04 \\
(0.07)\end{array}$ \\
\hline free rider & $0 . \overline{2} \overline{1}^{-}$ & $-0.26^{* * *}$ & -0.02 & 0.03 & $-0.33^{* *}$ & $-0.39 * * *$ & $-0.29 * * *$ & $-0.32 * * *$ \\
\hline & $(0.10)$ & $(0.10)$ & $(0.12)$ & $(0.14)$ & $(0.15)$ & $(0.15)$ & $(0.08)$ & $(0.08)$ \\
\hline obey authority & & $\begin{array}{c}0.09 \\
(0.06)\end{array}$ & & $\begin{array}{l}-0.04 \\
(0.05)\end{array}$ & & $\begin{array}{l}-0.07 \\
(0.06)\end{array}$ & & $\begin{array}{c}0.03 \\
(0.04)\end{array}$ \\
\hline demand of punish & & $\begin{array}{l}-0.03 \\
(0.05)\end{array}$ & & $\begin{array}{l}0.007 \\
(0.04)\end{array}$ & & $\begin{array}{c}0.16^{* * * *} \\
(0.06)\end{array}$ & & $\begin{array}{c}0.03 \\
(0.03)\end{array}$ \\
\hline locus of control & & $\begin{array}{c}0.01 \\
(0.05)\end{array}$ & & $\begin{array}{c}0.02 \\
(0.05)\end{array}$ & & $\begin{array}{c}0.08 \\
(0.05)\end{array}$ & & $\begin{array}{c}0.04 \\
(0.04)\end{array}$ \\
\hline collectivism & & $\begin{array}{l}0.004 \\
(0.05)\end{array}$ & & $\begin{array}{l}0.03 \\
(0.05)\end{array}$ & & $\begin{array}{l}-0.04 \\
(0.06)\end{array}$ & & $\begin{array}{l}-0.003 \\
(0.04)\end{array}$ \\
\hline competitiveness & & $\begin{array}{l}-0.03 \\
(0.05)\end{array}$ & & $\begin{array}{c}0.03 \\
(0.04)\end{array}$ & & $\begin{array}{l}0.006 \\
(0.05)\end{array}$ & & $\begin{array}{l}-0.02 \\
(0.03)\end{array}$ \\
\hline age & & $\begin{array}{l}-0.04 \\
(0.04)\end{array}$ & & $\begin{array}{l}0.06^{*} \\
(0.03)\end{array}$ & & $\begin{array}{l}-0.007 \\
(0.01)\end{array}$ & & $\begin{array}{l}-0.01 \\
(0.01)\end{array}$ \\
\hline gender & & $\begin{array}{l}-0.12 \\
(0.10)\end{array}$ & & $\begin{array}{c}0.11 \\
(0.09)\end{array}$ & & $\begin{array}{l}-0.14 \\
(0.15)\end{array}$ & & $\begin{array}{l}-0.09 \\
(0.08)\end{array}$ \\
\hline education & & $\begin{array}{l}0.22 * \\
(0.13)\end{array}$ & & $\begin{array}{l}-0.18 \\
(0.12)\end{array}$ & & $\begin{array}{l}-0.009 \\
(0.05)\end{array}$ & & $\begin{array}{l}0.015 \\
(0.04)\end{array}$ \\
\hline owe money & & $\begin{array}{l}0.34^{*} \\
(0.20)\end{array}$ & & $\begin{array}{l}-0.07 \\
(0.20)\end{array}$ & & $\begin{array}{l}-0.01 \\
(0.12)\end{array}$ & & $\begin{array}{l}-0.007 \\
(0.09)\end{array}$ \\
\hline happiness & & $\begin{array}{c}0.03 \\
(0.04)\end{array}$ & & $\begin{array}{l}0.002 \\
(0.04)\end{array}$ & & $\begin{array}{c}0.05 \\
(0.04)\end{array}$ & & $\begin{array}{c}0.02 \\
(0.03)\end{array}$ \\
\hline life satisfaction & & $\begin{array}{l}-0.02 \\
(0.04)\end{array}$ & & $\begin{array}{l}-0.06 \\
(0.04)\end{array}$ & & $\begin{array}{c}0.02 \\
(0.04)\end{array}$ & & $\begin{array}{c}0.02 \\
(0.03)\end{array}$ \\
\hline willingness to take risk & & $\begin{array}{c}0.04 \\
(0.03)\end{array}$ & & $\begin{array}{c}0.07 * * \\
(0.03)\end{array}$ & & $\begin{array}{c}0.02 \\
(0.02)\end{array}$ & & $\begin{array}{l}0.04 * * \\
(0.02)\end{array}$ \\
\hline $\begin{array}{l}\text { round } \\
\text { student }\end{array}$ & $\begin{array}{c}0.01 \\
(0.03)\end{array}$ & $\begin{array}{c}0.01 \\
(0.04)\end{array}$ & & $\begin{array}{c}-0.12 * * * \\
(0.04)\end{array}$ & $\begin{array}{l}-0.06 \\
(0.05)\end{array}$ & $\begin{array}{l}-0.05 \\
(0.06)\end{array}$ & $\begin{array}{c}-0.02 \\
(0.03) \\
-0.16^{* * *} \\
(0.06)\end{array}$ & $\begin{array}{l}-0.02 \\
(0.03) \\
-0.15 \\
(0.11)\end{array}$ \\
\hline $\begin{array}{l}\text { Observations } \\
\text { r2_p }\end{array}$ & $\begin{array}{l}150 \\
0.06\end{array}$ & $\begin{array}{l}143 \\
0.15\end{array}$ & $\begin{array}{l}150 \\
0.02\end{array}$ & $\begin{array}{l}143 \\
0.15\end{array}$ & $\begin{array}{l}149 \\
0.03\end{array}$ & $\begin{array}{l}124 \\
0.14\end{array}$ & $\begin{array}{l}299 \\
0.05\end{array}$ & $\begin{array}{l}267 \\
0.10\end{array}$ \\
\hline
\end{tabular}

Standard errors in parentheses; $* * * \mathrm{p}<0.01, * * \mathrm{p}<0.05, * \mathrm{p}<0.1$. In the student sample, conditional co-operators are more likely to vote for the introduction of the law $(\mathrm{p}<0.10)$, free riders are less likely to vote for the law $(\mathrm{p}<0.05)$, and conditional co-operators are more likely to pay money for the possibility of voting $(p<0.10)$. However, 
conditional co-operators of workers prefer not to have the law introduced. Thus this negative effect makes conditional co-operators not significant any more in pooled sample. Risk taking in real life becomes positively related to voting for the law for pooled sample and to paying for the law for students.

\subsection{Robustness check for independence of observations: Ordering effects}

We implemented the experiment as a within-subject design and thus our data in later rounds might be affected in some way by previous exposition to another treatment or even expectation of later treatments. Kamei (2015) recently showed that there might be spill-over effects of democratic participation in decision-making to subsequent decisions. Thus, deciding under EndoLaw might also lead to higher cooperation in the following rounds of ExoNoLaw or ExoLaw. Note that we do not expect such problems to occur because we did not find a positive effect of EndoLaw at all, and we tried to balance treatments across rounds as much as possible. In that sense, we have a between-subject design for each round, where round effects do not play a role. Our design thus combines the advantages of between- and within-subject designs. Looking only at the second round where we started to implement our three treatments, we can calculate a clean between-subject design, which is unaffected by any previous treatment and still has a considerable sample size of 269 observations. ${ }^{15}$ Participants starting the experiment with ExoNoLaw contributed on average $5.1(\mathrm{n}=60)$, compared to $5.4(\mathrm{n}=149)$ in EndoLaw and 6.3 in $\operatorname{ExoLaw}(\mathrm{n}=60)$. These figures are slightly higher compared to the within-subject design reported in Figure 1, where participants contribute on average $4.6(\mathrm{n}=299)$ in ExoNoLaw, compared to 5.0 (n=299) in EndoLaw and 6.0 in ExoLaw (n=299); however, the relative advantage of ExoLaw is remarkably similar. The pattern of declining contributions in public goods over time is a robust

\footnotetext{
${ }^{15}$ All participants in the first round carried out the conditional cooperation task. This might have primed all subjects to behave like conditional players. We do not believe that such priming took place, as we do not observe an information effect under EndoLaw.
} 
finding and not surprising. With the smaller sample sizes, ExoLaw is significantly better than ExoNoLaw (t-value=1.75). For the one-sided test, ExoLaw is also better than EndoLaw (tvalue=1.42). We report results from a regression-based test on round effects in the supplementary appendix. In addition, it might be indicative to compare contributions under ExoNoLaw to the unconditional contribution decision from round one. In order to elicit cooperator types, participants need to give their conditional contribution levels $[0 \ldots 10]$ as well as one unconditional decision. While the average contribution in ExoNoLaw over rounds two to four is $47 \%$, it is 48 $\%$ in the first round. Again, this suggests that behavior over rounds did not differ from a perfectly independent measure.

To further test for round effects and the stability of our estimates, we rely on a panel regression that pools all individuals and their relevant decisions across rounds. We regress individual contribution decisions on their decision type (ExoLaw, Endo0, Endo1 and Endo2 relative to the left out category ExoNoLaw) controlling for round and using individual fixed effects. We conduct this analysis separately for the subsamples of students/workers and Yes/No voters. The reason is that if results remain stable for these subsamples, they will also be for more aggregate samples. Table VII below shows the regression results in the columns "Panel regression". Even though there are round effects on contributions (mostly decreasing contributions over time), our treatment effects remain very similar to what would be predicted by our descriptive results. Those descriptive differences between ExoNoLaw and the other decision categories are calculated and shown for each of the subsamples in the columns "Descriptive difference". Testing for statistically significant differences between our panel regression coefficients and the descriptive differences results in very low significance levels (p-values 
between 0.54 and 1.00 , mostly greater or equal to 0.85 ). We can therefore be confident that our analysis is not biased by round effects.

\section{TABLE VII}

Contribution differences between ExoNoLaw and other decisions for different subpopulations;

Descriptive results versus regression controlling for round effects

\begin{tabular}{|c|c|c|c|c|c|c|c|c|c|c|c|c|}
\hline & & $\begin{array}{l}(1) \\
\text { tudent/ } \\
\text { To-voter }\end{array}$ & & & $\begin{array}{l}(2) \\
\text { Norker/ } \\
\text { To-voter }\end{array}$ & & & $\begin{array}{l}\text { (3) } \\
\text { tudent/ } \\
\text { es-voter }\end{array}$ & & & $\begin{array}{l}(4) \\
\text { Worker/ } \\
\text { es-voter }\end{array}$ & \\
\hline & $\begin{array}{l}\begin{array}{l}\text { Descriptive } \\
\text { difference }\end{array} \\
\end{array}$ & $\begin{array}{c}\text { Panel } \\
\text { regression }\end{array}$ & p-value & $\begin{array}{l}\begin{array}{l}\text { Descriptive } \\
\text { difference }\end{array} \\
\end{array}$ & $\begin{array}{c}\text { Panel } \\
\text { regression }\end{array}$ & p-value & $\begin{array}{l}\text { Descriptive } \\
\text { difference }\end{array}$ & $\begin{array}{c}\text { Panel } \\
\text { regression }\end{array}$ & p-value & $\begin{array}{l}\begin{array}{l}\text { Descriptive } \\
\text { difference }\end{array} \\
\end{array}$ & $\begin{array}{c}\text { Panel } \\
\text { regression }\end{array}$ & p-value \\
\hline ExoLaw & 0.88 & $0.90 * *$ & 0.95 & 1.25 & $1.25^{* * *}$ & 1.00 & 2.98 & $3.01 * * *$ & 0.96 & 0.78 & $0.78^{*}$ & 0.99 \\
\hline Endo0 & -0.20 & -0.27 & 0.86 & -0.77 & -0.60 & 0.71 & -0.69 & -0.72 & 0.96 & -2.24 & $-2.53 * * *$ & 0.54 \\
\hline Endo1 & -0.03 & -0.097 & 0.85 & -0.81 & -0.64 & 0.71 & 3.45 & $3.42 * * *$ & 0.96 & 1.23 & $0.94 *$ & 0.54 \\
\hline Endo2 & 0.95 & $0.88 * *$ & 0.85 & 0.01 & 0.18 & 0.71 & 3.45 & $3.42 * * *$ & 0.96 & 1.32 & $1.03 * *$ & 0.54 \\
\hline Round & & -0.15 & & & $0.33^{*}$ & & & -0.092 & & & $-0.44 * *$ & \\
\hline $\mathrm{N}$ & & 505 & & & 360 & & & 245 & & & 385 & \\
\hline
\end{tabular}

Note. The descriptive difference is compared to the corresponding Panel regression coefficients of contributions on round and game type with individual fixed-effects. The p-values give significance levels of a test on equality between the two. *** $\mathrm{p}<0.01, * * \mathrm{p}<0.05$, $* \mathrm{p}<0.1$, for each individual five contribution decisions are in the data (NoLaw, ExoLaw, Endo0, Endo1, Endo2). Observations in EndoPay are dropped.

\subsection{Discussion}

The central claim in our paper is that informal institutions determine the effectiveness of formal institutions. We found that individual values of accepting or obeying authorities are major determinants for the effectiveness of cooperation in top-down policymaking in China. Our findings are consistent with the work by Iyengar and Lepper (1999) on the intrinsic motivation of Asian American children, and our findings are consistent with the idea that humans are normadopting individuals who are influenced by the broader context they live in (e.g. (Poteete, Janssen, and Ostrom 2010; Boyd and Richerson 1988; Boyd and Richerson 2009, 1994; Gintis 2007)).

We think that the individual values elicited in our survey reflect past and current social norms and political conditions of China. While current norms and values have been described by Hofstede, Hofstede, and Minkov (2010), Inglehart and Welzel (2005), and House et al. (2004), it 
was pointed out by Giuliano and Nunn (2013) that China does not have a tradition of villagelevel democracy. In Late Imperial China, the Chinese state reinforced authoritarian patrilineal lineage structures throughout the Empire (Faure 2007). ${ }^{16}$ As Tsai (2007) could show in a celebrated comparative study of hundreds of Chinese villages, these traditional structures are still present today and prove to be a major determinant of the level of public goods provision. Interestingly, they can be more powerful in eliciting local cooperation and, in particular, accountability of local leaders than the formal structures of village elections that have been propagated all over China by the government over the last two decades. At the same time, failures of authoritarian leadership also undermine the democratic procedures of formal village elections (O'Brien and Han 2009; Yao 2013).

Compared to other East Asian societies, China did not experience a strong role of public intervention in educational systems that aimed to support externally imposed democratic political systems after World War II. Communist rule smoothly connects with earlier Imperial traditions of authoritarian paternalism, an observation highlighted in early studies on Chinese political culture (Pye (1968); for recent evaluations, see the review ( $\mathrm{Ng} \mathrm{2010)).} \mathrm{This} \mathrm{is} \mathrm{also} \mathrm{expressed} \mathrm{in}$ the revival of traditional values in education, even in grassroots movements (Billioud 2011). In the context of foreign-invested companies, "sinicization" of corporate culture often enhances authoritarian paternalism: For example, in Wal-Mart China, Sam Walton's management philosophy is interpreted in consonance with Confucian values and even Maoist thinking (Davies 2007). Making individual choices is neither part of the daily routines of students nor workers. Hence, we believe that there is ample evidence for the prevalence of values and norms for accepting authorities today and simultaneously high levels of cooperation. 
Another possibility to identify the effect of informal institutions on formal institutions (which we did not follow) is to carry out experiments in several countries that differ in their political and cultural values (i.e. from authoritarian to transition and democratic). This approach relates to studies by Henrich et al. (2005), Herrmann, Thöni, and Gächter (2008), and Cameron et al.(2009), who documented different patterns of behavior in the laboratory across small-scale societies and even countries. This is certainly an interesting avenue for future research, but this approach also has a small sample of countries and omitted variables. Thus, repeating the experiment in other countries would not allow the attribution of the differences between countries to one certain factor, as the countries in question differ in more than one dimension. For our Chinese case, one could also think of carrying out experiments and value surveys with migrants (see, e.g., Barr and Serra (2010)) in their new countries or returning migrants when they return to China. Our current experimental strategy differs notably from the cross-cultural experiments in that our identification of values on performance of institutions comes from differences between individuals within the same country and not from differences across countries. We thereby also circumvent problems of interpreting survey items between countries and other challenges inherent in cross-cultural research (i.e. comparability of stakes, sample, lab environment, etc.). Most importantly, in our case, absolute values for obeying authorities from the World Value Survey are not much higher in China compared to Western countries (compare Dalton and Ong 2005). Methodological assessments of international value studies have made the point that the resulting values do not represent absolute values, but marginal valuations; therefore, they cannot be directly compared in a cross-section. Marginal valuations are strongly contextualized, especially relative to reference points. For example, in a country with high absolute realizations of values, marginal valuation might be even relatively low (Beugelsdijk and Maseland 2010). ${ }^{17}$ 
As with all laboratory experiments, one can question how externally valid our results are. However, laboratory results from prior studies in the Western world are consistent with field evidence on participation and cooperation (Ichniowski and Shaw 2003; Zwick 2004; Casey et al. 2012; Pommerehne and Weck-Hannemann 1996; Bardhan 2000; Sekher 2000; Yoder 1994; Lam 1998). Another aspect is that democracy is much more than our stylized bipolar taxonomy. However, this bipolar classification is favorable to other specifications (Cheibub et al. 2010). Neither do we consider representative democracy nor do we perfectly mimic authoritarian leadership with our experiment (in our case, the authority were the experimenters). We also only focus on non-deterrent laws where the expressive function of the law is important. Therefore, future research should further try to establish causality of these results and confirm them in different experimental contexts and different countries.

\subsection{Literature for Appendix}

Bardhan, P. 2000. "Irrigation and cooperation: An empirical analysis of 48 irrigation communities in South India." Economic Development and Cultural Change 48 (4):847-65.

Barr, Abigail, and Danila Serra. 2010. "Corruption and culture: An experimental analysis." Journal of Public Economics 94 (11):862-9.

Beugelsdijk, Sjoerd, and Robbert Maseland. 2010. "Culture in economics: History, methodological reflections and contemporary applications", Cambridge University Press, Cambridge.

Billioud, Sébastien. 2011. "Confucian Revival and the Emergence of "Jiaohua Organizations": A Case Study of the Yidan Xuetang." Modern China. 37 (3):286-314.

Boyd, Robert, and Peter J. Richerson. 1988. "Culture and the Evolutionary Process", University of Chicago Press, Chicago. 
_. 1994. "The evolution of social norms: An anthropological view." Journal of Institutional and Theoretical Economics 150 (1):72-87.

_. 2009. "Culture and the evolution of human cooperation." Philosophical Transactions of the Royal Society B-Biological Sciences 364 (1533):3281-8.

Cameron, Lisa, Ananish Chaudhuri, Nisvan Erkal, and Lata Gangadharan. 2009. "Do Attitudes Towards Corruption Differ Across Cultures? Experimental Evidence from Australia, India, Indonesia and Singapore." Journal of Public Economics 93:843-51.

Cappelli, Peter, and David Neumark. 2001. "Do "high-performance" work practices improve establishment-level outcomes?." Industrial \& Labor Relations Review 54 (4):737-775.

Casey, Katherine, Rachel Glennerster, and Edward Miguel. 2012. "Reshaping Institutions: Evidence on Aid Impacts Using a Preanalysis Plan." Quarterly Journal of Economics 127 (4):1755-812.

Cheibub, Jose Antonio, Jennifer Gandhi, and James Raymond Vreeland. 2010. "Democracy and dictatorship revisited." Public Choice 143 (1):67-101.

Dal Bo, Pedro, Andrew Foster, and Louis Putterman. 2010. "Institutions and Behavior: Experimental Evidence on the Effects of Democracy." American Economic Review 100 (5):2205-29.

Dalton, Russel J. and Nhu-Ngoc T. Ong 2005. "Authority orientations and democratic attitudes: A test of the 'Asian values' hypothesis." Japanese Journal of Political Science 6(2): 211-231. Davies, David J. 2007. "Wal-Mao: The discipline of corporate culture and studying success at Wal-Mart China." The China Journal (58): 1-27.

Faure, David. 2007. "Emperor and Ancestor: State and Lineage in South China". Stanford University Press, Stanford. 
Feldman, Stanley. 2003. "Enforcing social conformity: A theory of authoritarianism." Political Psychology $24(1): 41-74$.

Giné, Xavier, Robert Townsend, and James Vickery. 2008. "Patterns of rainfall insurance participation in rural India." The World Bank Economic Review 22 (3):539-566.

Gintis, Herbert. 2007. "A framework for the unification of the behavioral sciences." Behavioral and Brain Sciences 30 (1):1-61.

Giuliano, Paola, and Nathan Nunn. 2013. "The Transmission of Democracy: From the Village to the Nation-State." American Economic Review 103 (3):86-92.

Godard, John, and John T. Delaney. 2000. "Reflections on the "High Performance" Paradigm's Implications for Industrial Relations as a Field" Industrial and Labor Relations Review 53 (3):482-502.

Henrich, Joseph, Robert Boyd, Samuel Bowles, Colin F. Camerer, Ernst Fehr, Herbert Gintis, Richard McElreath, Michael S. Alvard, Abigail Barr, Jean Ensminger, Natalie Smith Henrich, Kim Hill, Francisco Gil-White, Michael Gurven, Frank W. Marlowe, John Q. Patton, and David P. Tracer. 2005. "'"Economic man" in cross-cultural perspective: behavioral experiments in 15 small-scale societies." Behavioral and Brain Sciences 28:795815.

Herrmann, Benedikt, Christian Thöni, and Simon Gächter. 2008. "Antisocial Punishment across Societies." Science 319 (5868):1362-7.

Hofstede, Geert, Gert Jan Hofstede, and Michael Minkov. 2010. Cultures and Organizations: Software of the Mind, Third Edition: McGraw-Hill Education.

House, Robert J., Paul J. Hanges, Mansour Javidan, Peter W. Dorfman, and Vipin Gupta. 2004. "Culture, leadership, and organizations: The GLOBE study of 62 societies" Sage Publications. 
Ichniowski, Casey, and Kathryn Shaw. 2003. "Beyond incentive pay: Insiders' estimates of the value of complementary human resource management practices." Journal of Economic Perspectives 17 (1):155-80.

Inglehart, R. and C. Welzel 2005. "Modernization, cultural change, and democracy: The human development sequence". Cambridge University Press, Cambridge.

Iyengar, Sheena S, and Mark R. Lepper. 1999. "Rethinking the value of choice: a cultural perspective on intrinsic motivation." Journal of Personality and Social Psychology 76 (3):349.

Kamei, Kenju, Louis Putterman, and Jean-Robert Tyran. 2015. "State or nature? Endogenous formal versus informal sanctions in the voluntary provision of public goods" Experimentl Economics 18 (1):38-65.

Lam, Wai Fung. 1998. “Governing Irrigation Systems in Nepal: Institutions, Infrastructure, and Collective Action". ICS Press, Oakland.

Ng, Isabel. 2010. "Chinese political psychology: political participation in Chinese societies." The Oxford Handbook of Chinese Psychology:563-578.

O'Brien, Kevin J., and Rongbin Han. 2009. "Path to democracy? Assessing village elections in China." Journal of contemporary China 18 (60):359-78.

Ostrom, Elinor 1990. "Governing the commons: The evolution of institutions for collective action" Cambridge university press, Cambridge.

Pommerehne, Werner W., and Hannelore Weck-Hannemann. 1996. "Tax rates, tax administration and income tax evasion in Switzerland." Public Choice 88 (1-2):161-70.

Poteete, Amy R., Marco A. Janssen, and Elinor Ostrom. 2010. "Working Together: Collective Action, The Commons, and Multiple Methods in Practice" Princeton University Press, Princeton. 
Pye, Lucian W. 1968. "The spirit of Chinese politics: A psychocultural study of the authority crisis in political development." Massachusetts Institute of Technology Press.

Sekher, Madhushree. 2000. "Local Organisations and Participatory CPR Management: Some Reflections." ed. I. f. S. a. E. Change. Bangalore, India.

Stenner, Karen 2005. "The Authoritarian Dynamic” Cambridge Universit Press 28 (4):509-513.

Sutter, Matthias, Stefan Haigner, and Martin G. Kocher. 2010. "Choosing the Carrot or the Stick? Endogenous Institutional Choice in Social Dilemma Situations." Review of Economic Studies 77 (4):1540-66.

Tsai, Lily L. 2007. “Accountability without Democracy, Solidary Groups and Public Goods Provision in Rural China" Cambridge University Press, Cambridge.

Tyran, Jean R., and Lars P. Feld. 2006. "Achieving compliance when legal sanctions are nondeterrent." Scandinavian Journal of Economics 108 (1):135-56.

Whyte, Martin King. 2010. "One country, two societies: rural-urban inequality in contemporary China”. Vol. 16: Harvard University Press.

Yao, Yusheng. 2013. "Village Elections and Their Impact An Investigative Report on a Northern Chinese Village." Modern China 39 (1):37-68.

Yoder, Robert. 1994. "Locally Managed Irrigation Systems". International Irrigation Management Institute, Colombo.

Zwick, Thomas. 2004. "Employee participation and productivity." Labour Economics 11 (6):71540. 


\section{Appendix C: Experimental protocol, decision sheet and visualization}

When participants arrive

[Each participant arriving gets a random player number. Prepare cards with participant IDs corresponding to the seat numbers in the room, so that participants can be randomly allocated to seats.]

"Good afternoon, we are glad that you are participating in our experiment. You will learn in the lab what the experiment is about. In our experiment you will be divided into groups of three members. Therefore, we need a number of participants that is divisible by three. Now there are $[\mathrm{xx}]$ people present."

If the number of show-ups is divisible by three: "We can now begin the experiment".

[Participants are assigned a seat according to the player number. All participants are seated behind blinds facing outwards.]

If the number of show-ups is not divisible by three: "The number of participants needs to be divisible by three. Currently, xx people are present. Is there anybody who would like to leave voluntarily?"... "In case there are no volunteers, we will choose the participants by a lottery: Everybody has to draw a card with a participation ID on it. This number corresponds to the seat number. Those who draw a card with an X on it cannot participate and receive [the show-up fee]."

\section{$\underline{\text { Basic instructions }}$}

Thank you all for coming today. In this experiment today you can earn a considerable amount of money you are permitted to keep and take home. You must understand that this is not [Name of experimenter] private money but given to him by their university for research. If you read the following instructions carefully, you can, depending on your decisions and the decisions of the other participants, earn a considerable amount of money. It is therefore very important that you listen to these instructions with care. We are interested in your decision during the experiment. However, there are no "right" or "wrong" answers.

The experiment is divided into four/five rounds. In each round the participants are divided into groups of three. You will therefore be in a group with two other participants. In each round, the composition of your group will change: your probability of interacting more than one time with the same two people is very low. You will not be informed of the identity of the other group members. You will be paid 10 Yuan for coming to the experiment plus the additional earnings that you have kept during one of the four experimental rounds.

During this experiment we will not speak in terms of Yuan, but in points. At the end of the experiment the total amount of points you have earned in the selected round will be converted to Yuan at the following rate:

$$
1 \text { point }=1 \text { Yuan }
$$

After the experiment you have to answer a questionnaire. Then, each player will come one by one to [insert name of experimenter], who will hand out these earnings to you and you sign the receipt and are free to leave.

Some important remarks before we can start:

1. The experiment will take about two hours, including waiting time. If you find that this experiment is something that you do not wish to participate in for any reason, or you already know that you will not be able to stay for the two hours, please let us know immediately so that we can replace you with somebody else.

2. In the experiment, your identity will be kept anonymous. This means that except for [Name of experimenter], no one will come to know of your identity. I am interested only in the decisions made by you and not your identity. This is the reason that we will not ask your name in any of the experiment. We will identify your decision in the game with an identity card like this (show player ID card). Please do not lose this card.

3. It is very important that you understand the game. Therefore we will check your understanding by asking each of you test questions about the experiment. If you do not understand the experiment you may always ask the assistants to explain them. But if you cannot answer the test questions after explaining them again, we will have to exclude you from the experiment and you will receive 10 YUAN from us. Therefore, it is important that you listen to the instructions carefully. 
4. We would like to keep the game anonymous, therefore, please do not discuss the game with each other. In case we find that you are discussing the game with other players, we will exclude you immediately from the game. In this case, you will not receive any money.

5. If you have questions, always raise your hand and wait until one of the assistants comes to you. Then you can ask your question and the assistant will answer it. You are not allowed to talk to other participants during the experiment. You are not allowed to leave the room without permission. Please switch off your mobile phones and PCs. If you violate this rule, you will be dismissed from the experiment and forfeit all payments.

Thank you in advance for your effort and time.

At the beginning of the game, each player will receive ten Points from us. Now you have to decide how many from the ten Points to put into a private account and how many into a group project. You may put any amount between 0 and 10 Points into the project.

Now let us assume that out of 10 Points, you put zero Points into the project. Ask the group: Can you tell me how many Points there are in the project? How many Points does the player have in his private account? Have you understood this?

Now, let us assume that out of ten, you put one Point into the project. How many Points are in the project? How many Points does the player have in his private account? (Carry on with examples for 2, 5, 10Points). Have you understood this part? Do you need additional examples?

The following will happen with Points you contributed to the project: [Name of experimenter] will add 0.5 Points to each Points you and the other two group members contributed to the project. For example, if you put 0 Points into the project, the project amount will be increased by 0 Points. Now, the final amount of money in the project is 0 Points. If you put 1 point into the project, the project amount will be increased by 0.5 Points. Now, the final amount of money in the project is 1.5 Points. (Carry on with examples for 2, 5, 10Points). I repeat, the project amount will be increased by half the number of Points that you put in the project. Have you understood this? Do you need additional examples? (If yes, select another person and repeat the examples in the same order).

After the project money has increased, it will be divided equally between you and the other two players in your group, irrespective of how much you have put into the project (Please repeat this again). For example, if the project contains 0 Points, it will be increased by 0 Points and then divided equally between you and the other two players in your group. However, since zero does not increase, both you and the other two players will get zero Points from the project. For example, if the project contains 1 point, it will be increased by 0.5 Points. Now the total value of the project is 1.5 Points, and both you and the two other player get 0.5 Points each from the project (Carry on with examples for 2, 5, 10Points). Have you understood this part? Do you need additional examples?

Please remember that any money that you put into the project is first increased and then divided equally among the three players in your group. Any amount that you put in your pocket remains the same. If you put 1 point in your pocket, it remains 1 point. It neither increases nor is it divided.

Your final earning from the game is the sum of the amount you have in your pocket and the amount you receive from the project.

Let us make a few examples: Please note that since this is an example, we will tell how many Points to put into the project. But when we play the actual game, you will have to decide this on your own, without any help from us. Remember you have to decide how many Points you want to contribute to the project and how many Points you want to keep for yourself:

\section{[SHOW ALL EXAMPLES ON THE POSTER]}

1. Let us say you contribute 10 points to the project, the second member 6 points and the third member 0 points then the total group contribution is 16 points. For each Point contributed [Name of experimenter] adds 0.5 points. Thus, the sum is $16+8=24$ points. Because everybody of you receives the same income from the project, irrespective of your contribution, we divide the 24 points by 3 , which is 8 points. Thus, everybody of you will earn 8 points from the project. But remember, this is only the first part of your earning. To get your total earning, you have to add the Points you kept for yourself. Let's take a look at yours and the other group members' earnings: 
You contributed 10 points. Thus your earning from the private account is 0 . You get 8 points from the project. In total you receive $0+8=$ points 8 .

The second player contributed 6 points. His/her earning from the private account is therefore $(10-6)=4$ points. 4 points plus the 8 points from the project means a total earning of 12 points.

The third member of the group, who contributed nothing to the project, also gets 8 points from the project. Additionally he/she gets the 10 points he/she kept in his/her private account. His/her total income is therefore 18 Points.

2. The other two players decide to contribute 10 points to the project, you decide to contribute nothing. In this case the group contribution is $(10+10+0=) 20$ Points. For each Point contributed [Name of experimenter] adds 0.5 points. The sum is $20+10=30$ Points. Because everybody of you receives the same income from the project, irrespective of your contribution, we divide the 30 points by 3 , which is 10 Points. Thus, everybody of you will earn 10 Points from the project.

You will receive 10 Points from the project plus the 10 points you kept yourself $=20$ Points. The second and third member both contributed points 10, thus they did not put Points in their private accounts. Their total earnings are points 0 from the private account plus points 10 from the project is equal to 10 Points.

3. Each Player contributes all points 10 to the community project. Thus, the total contribution is 3 times $10=$ points 30. For each Points contributed, [Name of experimenter] will add 0.5 points. This sum is $30+15=45$ Points. 45 Points divided by 3 is 15 Points. Thus, everybody's earning from the project is 15 Points. Since nobody kept any Points for himself, this is also the total earning for everybody.

4. Each player decides to keep his Points for himself. Thus nobody contributes to the project. In that case everybody will earn 10 Points from the private account and nothing from the project, because none of you contributed to the project. Thus, the total income of each member is 10 Points.

If you have any questions, you may ask them now. Otherwise, we will call you one by one and ask seven questions to check if you have understood the game or not. Please note that if you answer these questions wrong, we will give you 10 Points and request you to leave the game venue. Therefore, please tell us if we need to repeat the examples or not (If yes, repeat the examples in the same order).

\section{Control questions}

1. How many points do you get at the start of the game?

2. What decision do you have to take in the game?

3. Suppose, you decide to put X points into the project, how much is left in your private account?

4. What happens to the money in the project?

5. If you put $\mathrm{X}$ points into the project, by how much will this increase?

6. If you put $\mathrm{X}$ points into the project and another player also puts $\mathrm{X}$ points into the project, who earns more?

7. If you put Y Points into the project and your partner puts Z Points into the project, who earns more?

(For those who answer 5-7 questions correctly, ask them to sit back in the room. Pay the remaining players 10 Yuan and request them to leave).

Additional question in EXOGENOUS

8. When does the deduction rule apply to you?

9. How many Yuan do we deduce from your earning if you put $\mathrm{X}[8,10]$ Yuan in the project? 


\section{Additional question in ENDOGENOUS}

10. When does the deduction rule apply to you? [Answer: If two people have voted for the deduction rule and I have contributed less than 10]

11. How many Yuan do we deduce from your earning if you put $X[8,10]$ Yuan in the project and zero of the other participants in the group have voted for the deduction rule?

12. How many Yuan do we deduce from your earning if you put $X[8,10]$ Yuan in the project and both you and another participants in the group have voted for the deduction rule?

13. How many Yuan do we deduce from your earning if you put $\mathrm{X}[8,10]$ Yuan in the project and both you and two other participants in the group have voted for the deduction rule?

\section{Additional question in ENDOPAY}

14. How can your group decide to have a deduction rule? [Answer: If at least two people have paid for the right to vote and two people voted for the deduction rule]

15. What happens if less than 2 participants in your group decide not to pay for the voting? [Answer: We will randomly decide whether your group will play with or without the rule]

16. What happens if more than 2 participants in your group decide to pay for the voting? [Answer: The group will vote whether to have the rule or not]

17. How many Yuan do we deduce from your earning if you put $X[8,10]$ Yuan in the project and zero of the other participants in the group have paid and voted for the deduction rule?

18. How many Yuan do we deduce from your earning if you put $\mathrm{X}[8,10]$ Yuan in the project and both you and another participants in the group have paid and voted for the deduction rule?

19. How many Yuan do we deduce from your earning if you put $\mathrm{X}[8,10]$ Yuan in the project and both you and two other participants in the group have paid and voted for the deduction rule? 


\section{Round 1}

Each player writes his decision on a decision sheet. Please remember that you will not come to know the identity of your partner players or the amount they put in the project. There you have to decide how many of your 10 points you want to contribute to the project. You can contribute any amount from 0 to 10. [Name of experimenter] will put your contribution into the project account and the remaining amount will be stored in your private account.

\section{Decision Task 1 [Unconditional decision]}

Each player writes his decision on a decision sheet without knowing what the other two players contribute to the project.

\section{Decision Task 2 [Conditional decision]}

In the first task, you did not know the amount the two other partner player put into the project. But in this task, we will ask you to decide how much you want to put in the project in case you know the Points your partner player put into the project. There are eleven decisions to be made in this game. Each decision is independent of the other. Please note that you will get a fresh endowment of ten Points at the start of each decision. We will now give you illustrations on how this game is played. Please listen carefully. While we give examples, no one is allowed to speak.

Example 1: The two other player in the game put on average out of ten - zero Points into the project (put no money on the table). Now, out of ten Points, how much would you like to put into the project? After you have made your decision, the decision is over.

Example 2: The two other player in the game put on average out of ten - one Points into the project (put one Points on the table). Now, out of ten Points, how much would you like to put into the project? After you have made your decision, the decision is over. (Carry on till 10 Points.)

After all participants in one group made their entries, a random device (computer choice) elects one subject of each group to be the "conditional contributor". This subject's contribution is determined by her contribution table. For the remaining two subjects the unconditional contribution is decisive.

Do you have any questions?

There are eleven decisions to be taken in this game. Your partner players on average puts 0 , how much would you like to put; Your partner players on average puts 1, how much would you like to put; Your partner players on average puts 2, how much would you like to put; Your partner players on average puts 3; how much would you like to put; Your partner players on average puts 4, how much would you like to put; Your partner players on average puts 5, how much would you like to put; Your partner players on average puts 6 , how much would you like to put. How many decisions do you have to take in this game? Your partner players on average puts 7, how much would you like to put. Your partner players on average puts 8, how much would you like to put. Your partner players on average puts 9, how much would you like to put. Your partner players on average puts 10, how much would you like to put. How many decisions do you have to take in this game?

At the beginning of each decision, you will get 10 Points, just like in the examples you saw. Each decision is independent of the other. A very important point is that we will pick only one of these eleven decisions to decide your earnings. So please take all the decisions seriously. Do you have any questions?

\section{Round 2-5}

\section{TREATMENT 1 (No law)}

The groups are reshuffled after the last round. You are randomly matched with two players from this room. Except [Name of experimenter], nobody knows who is in which group. Neither before, nor after the experiment, will you learn which people were in your group.

As before, at the beginning of the game, each player will receive ten Points from us. Now you have to decide how many from the ten Points to put into a private account and how many into a group project. You may put any amount between 0 and 10 Points into the project. You only make one decision and you do not know the contribution of the other two players to the group account.

\section{TREATMENT 2 (Exogenous rule)}


The groups are reshuffled after the last round. You are randomly matched with two players from this room. Except [Name of experimenter], nobody knows who is in which group. Neither before, nor after the experiment, will you learn which people were in your group.

As before, at the beginning of the game, each player will receive ten Points from us. Now you have to decide how many from the ten Points to put into a private account and how many into a group project. You may put any amount between 0 and 10 Points into the project. You only make one decision and you do not know the contribution of the other two players to the group account. Additional to the rules before this round is played with a deduction rule.

\section{Consequences of the deduction rule}

As explained before, your point income consists of your income from the private account plus the income from the group account. Each group member contributing less than 10 points to the group account will incur a deduction of 2 Points if the deduction rule is applied. To repeat, a member of your group will be deduced 2 Points of income if the following conditions apply:

1. The group has accepted the deduction rule (i.e. at least 2 group members vote yes).

2. The contribution of the group member to the group account is less than 10 Points.

Ask: Did everybody understand the deduction rule?

\section{TREATMENT 3 (Endogenous rule)}

The groups are reshuffled after the last round. You are randomly matched with two players from this room. Except [Name of experimenter], nobody knows who is in which group. Neither before, nor after the experiment, will you learn which people were in your group.

As before, at the beginning of the game, each player will receive ten Points from us. Now you have to decide how many from the ten Points to put into a private account and how many into a group project. You may put any amount between 0 and 10 Points into the project. You only make one decision and you do not know the contribution of the other two players to the group account. Before making your decision, you participate in a referendum on the introduction of a deduction rule.

\section{Referendum on the deduction rule}

You and the two other group members vote in a referendum on a deduction rule. The deduction rule will be applied if a majority of voters (i.e. 2 or 3 voters) approves of it. The deduction rule will not be applied if a minority (i.e. 0 or 1 voter) approves.

\section{Consequences of the deduction rule}

As explained before, your earning consists of your income from the private account plus the income from the group account. Each group member contributing less than 10 points to the group account will incur a deduction of 2 Points if the deduction rule is applied. To repeat, a member of your group will be deduced 2 Points of income if the following conditions apply:

1. The group has accepted the deduction rule (i.e. at least 2 group members vote yes).

2. The contribution of the group member to the group account is less than 10 Points.

Ask: Did everybody understand the referendum and the deduction rule? 


\section{TREATMENT 4 (EndoPay: pay for referendum \& endogenous rule)}

The groups are reshuffled after the last round. You are randomly matched with two players from this room. Except [Name of experimenter], nobody knows who is in which group. Neither before, nor after the experiment, will you learn which people were in your group.

As before, at the beginning of the game, each player will receive ten Points from us. Now you have to decide how many from the ten Points to put into a private account and how many into a group project. You may put any amount between 0 and 10 Points into the project. You only make one decision and you do not know the contribution of the other two players to the group account. Additional to the rules before this round starts with the possibility to implement a deduction rule.

\section{Pay for referendum}

You can influence whether you want to continue to play this game as before or with the possibility that players who are not contributing all their money to the group project get 2 Points deducted from their final earnings. The deduction rule can be implemented after a referendum. We first explain the process to have a referendum.

Your group can have a referendum when a majority of players in your groups (i.e. 2 or 3 players) decide to pay 2 yuan (similar to 2 points) from his/her show-up fee. When nobody or only one player pays 2 yuan of his showup fee we will randomly decide whether you will get a deduction rule or not.

If two or three players did pay 2 yuan (similar to 2 points), you and the two other group members vote in a referendum on a deduction rule. The deduction rule will be applied if a majority of voters (i.e. 2 or 3 voters) approves of it. The deduction rule will not be applied if a minority (i.e. 0 or 1 voter) approves.

\section{Consequences of the deduction rule}

As explained before, your point income consists of your income from the private account plus the income from the group account. Each group member contributing less than 10 points to the group account will incur a deduction of 2 Points if the deduction rule is applied. To repeat, a member of your group will be deduced 2 Points of income if the following conditions apply:

1. The group has paid to have a referendum (i.e. at least 2 group members pay 2 yuan from their show-up fee).

2. The group has accepted the deduction rule (i.e. at least 2 group members vote yes).

Or:

3. The contribution of the group member to the group account is less than 10 Points.

1. The group has not paid to have a referendum (i.e. less than 2 group members pay 2 yuan from their show-up fee).

2. We randomly decided to have the deduction rule ( $50 \%$ chance)

We will now distribute the decision sheets. You are not allowed to talk to others about your decisions. It is your private choice whether you want to pay for having a referendum and continue with the deduction rule or not. 
[All decision sheets were handed out and explained on a poster]

[Decision sheet for first round]

Player ID:

Your decision (integer number between 0 and 10)

\begin{tabular}{|l|}
\hline Your contribution to the group project \\
\hline
\end{tabular}

Please indicate for each possible average contribution level $(0,1,2,3,4,5,6,7,8,9,10)$ of the other group members how many of your 10 points you allocate to the group project.

\begin{tabular}{|c|l|}
\hline $\begin{array}{l}\text { Average contribution of the other two group } \\
\text { members to the group project }\end{array}$ & $\begin{array}{l}\text { Your conditional contribution to } \\
\text { the group project }\end{array}$ \\
\hline 0 & \\
\hline 1 & \\
\hline 2 & \\
\hline 3 & \\
\hline 4 & \\
\hline 5 & \\
\hline 6 & \\
\hline 7 & \\
\hline 8 & \\
\hline 9 & \\
\hline 10 & \\
\hline &
\end{tabular}

Note after all participants in one group made their entries, a random device (throw of a die) elects one subject of each group to be the "conditional contributor". This subject's contribution is determined by her contribution table. For the remaining two subjects the unconditional contribution is decisive. Note that only decision at the actual outcome will be relevant for your income.

\section{[Decision sheet for No Law] \\ Player ID:}

Your decision (integer number between 0 and 10)

Your contribution to the group project

\section{[Decision sheet for exogenous rule] \\ Player ID:}

Your decision (integer number between 0 and 10)

Your contribution to the group project

Remember: If you contribute less than 10 points, we will deduct 2 points. 


\section{[Decision sheet for endogenous rule]}

\section{Player ID:}

Referendum: Deduction rule

Each member of the group that contributes less than 10 points to the group account will incur a deduction of 2 points. Do you want to accept the deduction rule?
Yes
No

Please tick one.

Please note:

1. Your group consist of three people, including yourself.

2. The deduction rule passes if at least two (i.e. two or three) group members approve.

In case zero of the other two group members approves of the deduction rule (This means that there is no deduction rule.):

Your decision (integer number between 0 and 10)

\begin{tabular}{|l|}
\hline Your contribution to the group project \\
\hline
\end{tabular}

In case one of the other two group members approves of the deduction rule (This means that it's up to your voting decision whether there is a deduction rule or not.):

Your decision (integer number between 0 and 10)

Your contribution to the group project

In case two of the other two group members approve of the deduction rule (This means that there is a deduction rule.):

Your decision (integer number between 0 and 10)

\begin{tabular}{|l|}
\hline Your contribution to the group project \\
\hline
\end{tabular}




\section{[Decision sheet for Endo Pay] [Page 1]}

Player ID:

Proposal: Pay 2 Yuan from your show-up fee of ten Yuan for having a referendum on a deduction rule. A referendum will be held if at least two members of your group pay 2 Yuan.

Do you want to pay two Yuan for the referendum?

Please tick one.

$$
\text { Yes No }
$$

In case no group members or only one group member paid for the vote we randomly decide whether to have a deduction rule or not.

In case of no deduction rule, your decision (integer number between 0 and 10)

Your contribution to the group project

In case of a deduction rule, your decision (integer number between 0 and 10).

\begin{tabular}{|l|}
\hline Your contribution to the group project \\
\hline
\end{tabular}




\section{[Page 2 EndoPay]}

\section{Player ID:}

In case two or three group members paid for the vote there will be a referendum on the following rule: Each member of the group that contributes less than 10 points to the group account will incur a deduction of 2 points. Without knowing whether there will be a referendum would you want to accept the deduction rule?

Please tick one.

$$
\text { Yes No }
$$

Please note:

1. Your group consist of three people, including yourself.

2. The deduction rule passes if at least two (i.e. two or three) group members approve.

In case zero of the other two group members approves of the deduction rule (This means that there is no deduction rule.):

Your decision (integer number between 0 and 10)

\begin{tabular}{|l|}
\hline Your contribution to the group project \\
\hline
\end{tabular}

In case one of the other two group members approves of the deduction rule (This means that it's up to your voting decision whether there is a deduction rule or not.):

Your decision (integer number between 0 and 10)

\begin{tabular}{|l|}
\hline Your contribution to the group project \\
\hline
\end{tabular}

In case two of the other two group members approve of the deduction rule (This means that there is a deduction rule.):

Your decision (integer number between 0 and 10)

Your contribution to the group project


[Poster used to explain the examples for the public goods]

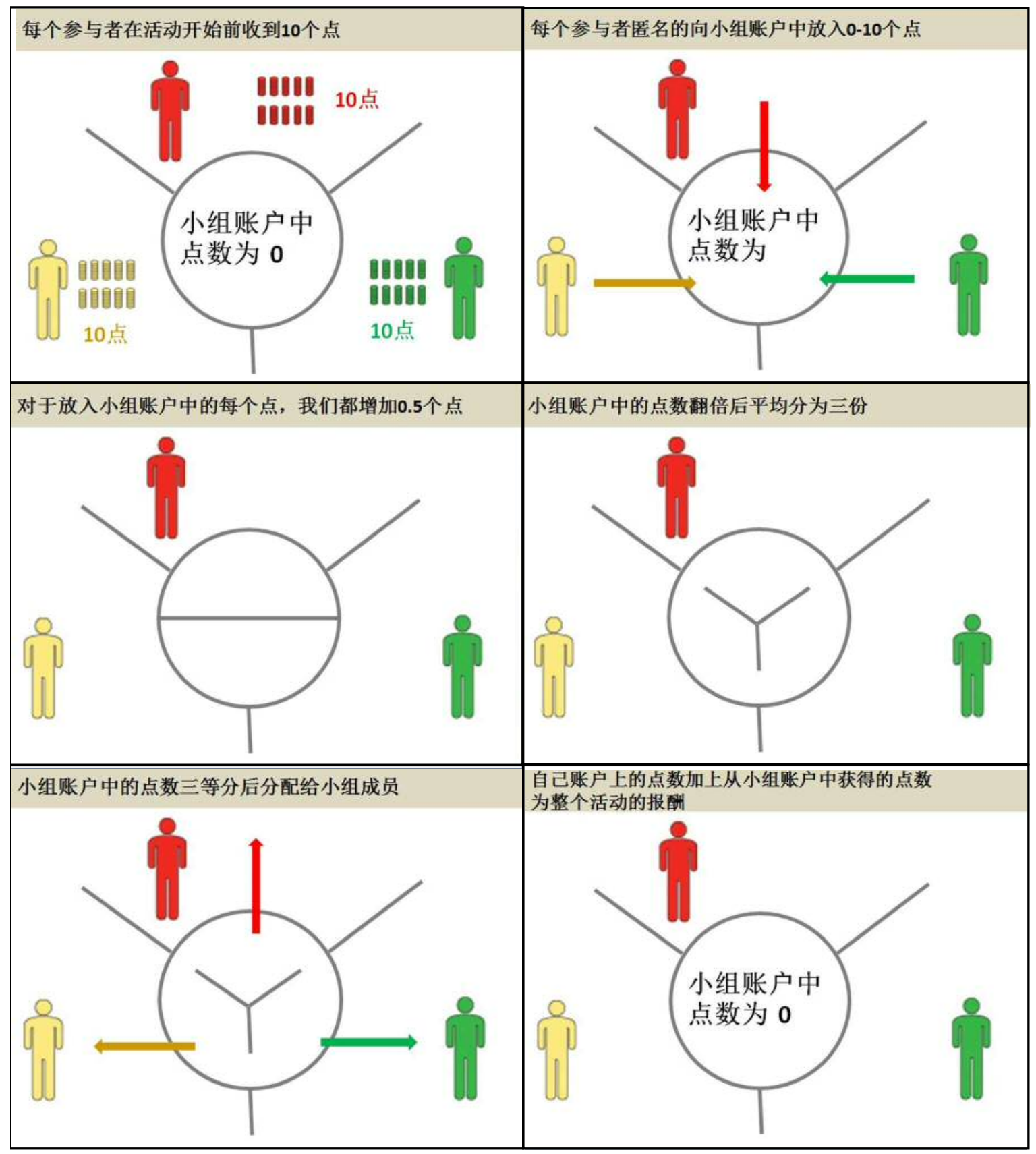


University of Innsbruck - Working Papers in Economics and Statistics Recent Papers can be accessed on the following webpage:

http://eeecon.uibk.ac.at/wopec/

2013-14 Björn Vollan, Yexin Zhou, Andreas Landmann, Biliang Hu, Carsten Herrmann-Pillath: Cooperation under democracy and authoritarian norms

2013-13 Florian Lindner, Matthias Sutter: Level-k reasoning and time pressure in the 11-20 money request game forthcoming in Economics Letters

2013-12 Nadja Klein, Thomas Kneib, Stefan Lang: Bayesian generalized additive models for location, scale and shape for zero-inflated and overdispersed count data

2013-11 Thomas Stöckl: Price efficiency and trading behavior in limit order markets with competing insiders forthcoming in Experimental Economics

2013-10 Sebastian Prediger, Björn Vollan, Benedikt Herrmann: Resource scarcity, spite and cooperation

2013-09 Andreas Exenberger, Simon Hartmann: How does institutional change coincide with changes in the quality of life? An exemplary case study

2013-08 E. Glenn Dutcher, Loukas Balafoutas, Florian Lindner, Dmitry Ryvkin, Matthias Sutter: Strive to be first or avoid being last: An experiment on relative performance incentives.

2013-07 Daniela Glätzle-Rützler, Matthias Sutter, Achim Zeileis: No myopic loss aversion in adolescents? An experimental note

2013-06 Conrad Kobel, Engelbert Theurl: Hospital specialisation within a DRGFramework: The Austrian case

2013-05 Martin Halla, Mario Lackner, Johann Scharler: Does the welfare state destroy the family? Evidence from OECD member countries

2013-04 Thomas Stöckl, Jürgen Huber, Michael Kirchler, Florian Lindner: Hot hand belief and gambler's fallacy in teams: Evidence from investment experiments

2013-03 Wolfgang Luhan, Johann Scharler: Monetary policy, inflation illusion and the Taylor principle: An experimental study

2013-02 Esther Blanco, Maria Claudia Lopez, James M. Walker: Tensions between the resource damage and the private benefits of appropriation in the commons 
2013-01 Jakob W. Messner, Achim Zeileis, Jochen Broecker, Georg J. Mayr: Improved probabilistic wind power forecasts with an inverse power curve transformation and censored regression

2012-27 Achim Zeileis, Nikolaus Umlauf, Friedrich Leisch: Flexible generation of e-learning exams in R: Moodle quizzes, OLAT assessments, and beyond

2012-26 Francisco Campos-Ortiz, Louis Putterman, T.K. Ahn, Loukas Balafoutas, Mongoljin Batsaikhan, Matthias Sutter: Security of property as a public good: Institutions, socio-political environment and experimental behavior in five countries

2012-25 Esther Blanco, Maria Claudia Lopez, James M. Walker: Appropriation in the commons: variations in the opportunity costs of conservation

2012-24 Edgar C. Merkle, Jinyan Fan, Achim Zeileis: Testing for measurement invariance with respect to an ordinal variable forthcoming in Psychometrika

2012-23 Lukas Schrott, Martin Gächter, Engelbert Theurl: Regional development in advanced countries: A within-country application of the Human Development Index for Austria

2012-22 Glenn Dutcher, Krista Jabs Saral: Does team telecommuting affect productivity? An experiment

2012-21 Thomas Windberger, Jesus Crespo Cuaresma, Janette Walde: Dirty floating and monetary independence in Central and Eastern Europe - The role of structural breaks

2012-20 Martin Wagner, Achim Zeileis: Heterogeneity of regional growth in the European Union

2012-19 Natalia Montinari, Antonio Nicolo, Regine Oexl: Mediocrity and induced reciprocity

2012-18 Esther Blanco, Javier Lozano: Evolutionary success and failure of wildlife conservancy programs

2012-17 Ronald Peeters, Marc Vorsatz, Markus Walzl: Beliefs and truth-telling: A laboratory experiment

2012-16 Alexander Sebald, Markus Walzl: Optimal contracts based on subjective evaluations and reciprocity

2012-15 Alexander Sebald, Markus Walzl: Subjective performance evaluations and reciprocity in principal-agent relations

2012-14 Elisabeth Christen: Time zones matter: The impact of distance and time zones on services trade 
2012-13 Elisabeth Christen, Joseph Francois, Bernard Hoekman: CGE modeling of market access in services

2012-12 Loukas Balafoutas, Nikos Nikiforakis: Norm enforcement in the city: A natural field experiment forthcoming in European Economic Review

2012-11 Dominik Erharter: Credence goods markets, distributional preferences and the role of institutions

2012-10 Nikolaus Umlauf, Daniel Adler, Thomas Kneib, Stefan Lang, Achim Zeileis: Structured additive regression models: An $\mathrm{R}$ interface to BayesX

2012-09 Achim Zeileis, Christoph Leitner, Kurt Hornik: History repeating: Spain beats Germany in the EURO 2012 Final

2012-08 Loukas Balafoutas, Glenn Dutcher, Florian Lindner, Dmitry Ryvkin: The optimal allocation of prizes in tournaments of heterogeneous agents

2012-07 Stefan Lang, Nikolaus Umlauf, Peter Wechselberger, Kenneth Harttgen, Thomas Kneib: Multilevel structured additive regression

2012-06 Elisabeth Waldmann, Thomas Kneib, Yu Ryan Yu, Stefan Lang: Bayesian semiparametric additive quantile regression

2012-05 Eric Mayer, Sebastian Rueth, Johann Scharler: Government debt, inflation dynamics and the transmission of fiscal policy shocks forthcoming in Economic Modelling

2012-04 Markus Leibrecht, Johann Scharler: Government size and business cycle volatility; How important are credit constraints? forthcoming in Economica

2012-03 Uwe Dulleck, David Johnston, Rudolf Kerschbamer, Matthias Sutter: The good, the bad and the naive: Do fair prices signal good types or do they induce good behaviour?

2012-02 Martin G. Kocher, Wolfgang J. Luhan, Matthias Sutter: Testing a forgotten aspect of Akerlof's gift exchange hypothesis: Relational contracts with individual and uniform wages

2012-01 Loukas Balafoutas, Florian Lindner, Matthias Sutter: Sabotage in tournaments: Evidence from a natural experiment published in Kyklos 


\title{
University of Innsbruck
}

\section{Working Papers in Economics and Statistics}

\section{3-14}

Björn Vollan, Yexin Zhou, Andreas Landmann, Biliang Hu, Carsten HerrmannPillath

Cooperation under democracy and authoritarian norms

\begin{abstract}
There is ample evidence for a "democracy premium". Laws that have been implemented via election lead to a more cooperative behavior compared to a top-down approach. This has been observed using field data and laboratory experiments. We present evidence from Chinese students and workers who participated in public goods experiments and a value survey. We find a premium for top-down rule implementation stemming from people with stronger individual values for obeying authorities. When participants have values for obeying authorities, they even conform to non-preferred rule. Our findings provide strong evidence that the efficiency of political institutions depends on societal norms.
\end{abstract}

ISSN 1993-4378 (Print)

ISSN 1993-6885 (Online) 